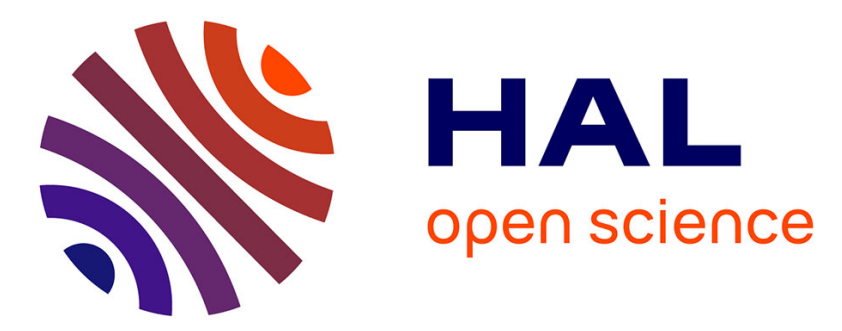

\title{
Nanocomposite Polymer Scaffolds Responding under External Stimuli for Drug Delivery and Tissue Engineering Applications
}

Damien Mertz, Sebastien Harlepp, Jacky Goetz, Dominique Begin, Guy Schlatter, Sylvie Bégin-colin, Anne Hebraud

\section{To cite this version:}

Damien Mertz, Sebastien Harlepp, Jacky Goetz, Dominique Begin, Guy Schlatter, et al.. Nanocomposite Polymer Scaffolds Responding under External Stimuli for Drug Delivery and Tissue Engineering Applications. Advanced Therapeutics, 2020, pp.1900143. 10.1002/adtp.201900143 . hal-02413350

\section{HAL Id: hal-02413350 https://hal.science/hal-02413350}

Submitted on 25 Nov 2020

HAL is a multi-disciplinary open access archive for the deposit and dissemination of scientific research documents, whether they are published or not. The documents may come from teaching and research institutions in France or abroad, or from public or private research centers.
L'archive ouverte pluridisciplinaire HAL, est destinée au dépôt et à la diffusion de documents scientifiques de niveau recherche, publiés ou non, émanant des établissements d'enseignement et de recherche français ou étrangers, des laboratoires publics ou privés. 
DOI: 10.1002/ (adtp.201900143R1)

\title{
Article type: Review
}

\section{Nanocomposite Polymer Scaffolds Responding Under External Stimuli for Drug Delivery and Tissue Engineering Applications}

Damien Mertz*, Sebastien Harlepp, Jacky Goetz, Dominique Bégin, Guy Schlatter, Sylvie Bégin-Colin, Anne Hébraud

Dr. Damien Mertz, Prof. Sylvie Bégin-Colin, Institut de Physique et Chimie des Matériaux de Strasbourg (IPCMS), UMR-7504 CNRSUniversité de Strasbourg, 23 rue du Loess, BP 34 67034, Strasbourg Cedex 2, France. E-mail: damien.mertz@ipcms.unistra.fr Dr. Sébastien Harlepp, Dr. Jacky Goetz, INSERM UMR_S1109, Tumor Biomechanics, Strasbourg, Université de Strasbourg, Fédération de Médecine Translationnelle de Strasbourg (FMTS), 67000 Strasbourg, France Dr. Dominique Bégin, Prof. Guy Schlatter, Dr. Anne Hébraud Institut de Chimie et Procédés pour l'Energie, l'Environnement et la Santé (ICPEES), UMR7515 CNRS-Université de Strasbourg, 25 rue Becquerel, 67087 Strasbourg, Cedex 2, France.

Keywords: responsive nanocomposites, external stimuli, polymer scaffolds, drug release, tissue engineering

\begin{abstract}
The blossoming development of nanomaterials and polymer science has opened the way towards new biocompatible scaffolds responding remotely to external stimuli (magnetic field, light, electric field). Such smart scaffolds are envisioned as new implantable tissues displaying multiple therapeutic and imaging functionalities. They hold great promises to achieve a controlled delivery of therapeutics for various diseases, or to ensure a stimuliinduced cellular response for bone, cardiac, or muscle tissue engineering.
\end{abstract}

\section{Table of content}

1. Introduction

2. Criteria and key issues to design smart stimuli responsive scaffolds for biomedicine

2.1 Biomedical issues: biocompatibility and immune response

2.2 Fabrication criteria for biomedical applications

2.3 Biomedical implementation of the remotely responsive scaffold 
3. From nanoparticles and polymers as building blocks to responsive nanocomposite scaffolds

3.1 Inorganic nanomaterials as ideal building blocks for signal conversion

3.2 Polymer scaffolds as host integrative matrix

3.3 Formulate polymer scaffolds and NPs: process, issues and physico-chemical features

4. Applications of nanocomposite scaffolds for controlled drug delivery

4.1 Drug delivery upon static magnetic field by magnetomechanical effects

4.2 Drug delivery upon an alternating magnetic field by magnetothermal effects

4.3 Photoresponsive scaffolds with drug delivery activated by near infra-red light

4.4 Electroresponsive scaffolds for transdermal drug delivery

5. Applications in Tissue Engineering

5.1 Bone regeneration

5.2 Soft actuators controlled by external fields and muscle tissue engineering

5.3 Cardiovascular tissue regeneration induced by external fields

5.4 Neuronal regeneration

6. Conclusion and Perspectives

\section{Acronym List :}

AMF: alternating magnetic field

CNTs: carbon nanotubes

DOX : doxorubicin

ECM: extracellular matrix

ELS: electrospun

EP: electroporation

GO: graphene oxide

IO NPs: iron oxide NPs

LCST: lower critical solution temperature 
MH: magnetic hyperthermia

MRF: magneto-rheological fluid

MRI: magnetic resonance imaging

MS: mesoporous silica

NIR: near infra-red light

NPs: nanoparticles

PAN: poly(acrylonitrile)

PCL: $\operatorname{poly}(\varepsilon$-caprolactone $)$

PEG: poly(ethylene glycol)

PEO: poly(ethylene oxide)

PLGA: poly(lactide-co-glycolide)

PLLA: poly(L-lactic acid)

PNIPAM: poly(N-isopropylacrylamide)

PU: polyurethane

PVA: poly(vinylalcohol)

PVP: poly(vinyl pyrrolidone)

SAR: specific absorption rate

SMF: static magnetic field

SPR: surface plasmon resonance

US: ultra-sound

\section{Introduction}

The design of smart and remotely responsive nanocomposite scaffolds emerged this last decade as a powerful strategy for applications in nanomedicine, biomaterials and tissue engineering. ${ }^{[1-4]}$ For instance, in some antitumoral treatments, important advantages are highlighted in the use of implants as alternatives to circulating nanomaterials. ${ }^{[5]}$ Indeed, by 
achieving a sustained delivery of therapeutics to a specific diseased tissue, these implants can ensure a local delivery of antitumor drugs to fight cancer, with an optimized dose and minimum loss of drugs administered avoiding side effects. In the area of tissue engineering, the controlled release of therapeutics (growth factors, anti-inflammatory agents or pain killers), is also highly needed. ${ }^{[4,6,7]}$ However, another emerging strategy is the possibility of remotely activating by external fields, tissue actuation for bone, cardiac, neuronal or muscle regeneration which should result in very attractive applications. ${ }^{[1-3,8,9]}$ Other emerging applications for which nanotechnology hold great promises also concerns the development of integrated systems or devices releasing antimicrobial agents to fight against biofilm formation at implant surface ${ }^{[10]}$ or insulin for glucose regulation in the case of diabetes, where an implanted biomaterial would be more convenient than injection. ${ }^{[11,12]}$ Hence, the development of smart new implants, remotely controlled by application of external fields could be very attractive to treat these diseases.

To respond to these biomedical challenges, the combination of a polymer scaffold with remotely responsive inorganic nanoparticles (NPs) emerges as a powerful approach to design a new generation of smart implantable scaffolds. Indeed, the incorporation of remotely responsive NPs brings numerous key advantages. First, the presence of NPs acting as nanofillers, help to substantially improve the mechanical properties of the polymer scaffolds. One of the main limitations of polymer scaffolds such as hydrogels for biomedical applications is probably their weak mechanical properties, in terms of viscoelasticity (low elastic modulus). Such mechanical features render them quite difficult to handle, or to stabilize after injection in vivo. Therefore, the incorporation of NPs within the scaffold could help solve the mechanical stability issue. ${ }^{[2,13,14]}$ Moreover, iron oxide, gold or carbon based NPs render the composite materials responsive to a wide range of external stimuli such as magnetic field, infrared light or electric field. ${ }^{[15-19]}$ For instance, the application of magnetic or photonic stimulus to the NPs embedded in the scaffold could result in local heating of the 
polymer matrix. When this matrix is a lower critical solution temperature (LCST) responsive polymer, i.e. a polymer that undergoes coil-to-globule transition above a certain temperature, local heating can then trigger different physical responses such as swelling, shrinking, distortions, content release etc. ${ }^{[20,21]}$ At least, the localization of NPs at the implant surface, inducing roughness or nanostructuration could also be highly attractive to ensure strong suitable adhesion between hydrogels and even between tissues. ${ }^{[22]}$

The topic of this review article is hence at the cutting edge of various scientific and biomedical fields: nanotechnology, polymer chemistry, biomaterial science and medicine. Herein, we address the design of nanocomposite scaffolds for biomedical applications responding to external fields: magnetic, light and electric (Figure 1). We focus on the design of nanocomposite scaffolds, from the synthesis of the building blocks to their assembly into a functional biomedical device. After discussing briefly the various criteria and specifications needed for these type of implants, the building blocks are described in detail: the responsive NPs (iron oxide, carbon and gold) are used to achieve remote optimized responses (magneto-, photo-thermal effects or electric conduction) while the polymer matrix such as hydrogels and electrospun (ELS) fibers provides the desired scaffold properties i.e., mechanical stability, thermal responsivity, hydrophilicity/hydrophobicity. Then, we describe methods (and related issues) to assemble both inorganic and polymer materials to create externally responsive nanocomposite polymer scaffolds. We provide key examples that illustrate the medical potential of such scaffolds for remote drug delivery and for tissue engineering (bone, muscle, cardiac and neuronal regeneration). Noteworthy, scaffolds incorporated with bioactive glasses and hydroxyapatites for bone regeneration ${ }^{[2,23]}$ or with silver NPs for antimicrobial applications $^{[10,24]}$ not used as remote stimuli-responsive NPs, were reviewed previously elsewhere in other well detailed reports and will be out of the scope of this review. 


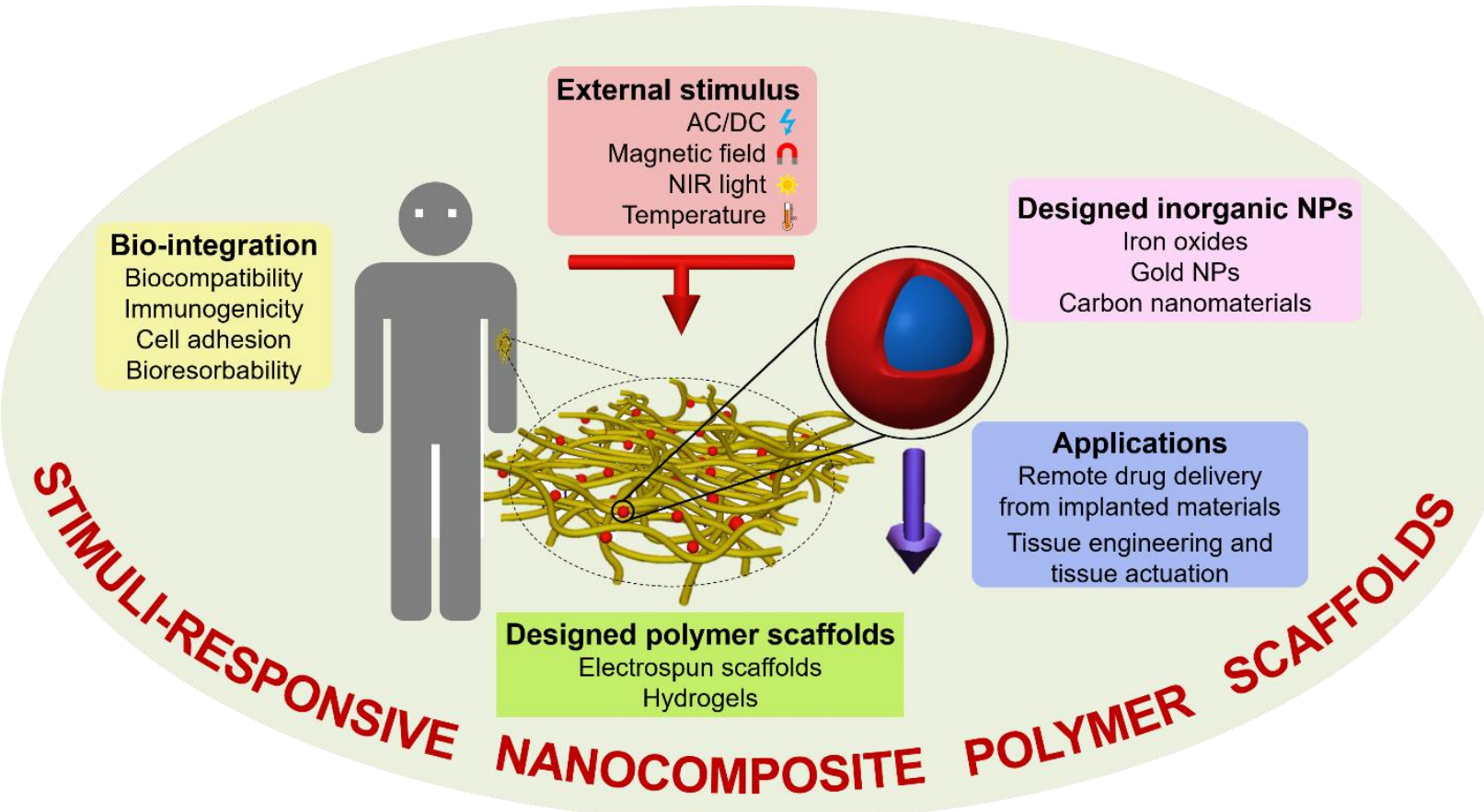

Figure 1. Scheme illustrating the components for the design of smart stimuli-responsive nanocomposite polymer scaffolds and their challenges for drug delivery and tissue engineering applications.

\section{Criteria and key issues to design smart stimuli responsive scaffolds for biomedicine}

\subsection{Biomedical issues: biocompatibility and immune response}

Human biocompatibility of engineered scaffolds is a key determinant of success for biomedical applications. Polymers, for example, hold great promise due to their biocompatibility, as well as their degradation/absorption rates in physiological settings. ${ }^{[25]}$ When designing nano-engineered scaffolds and aiming for biomedical applications such as tunable drug delivery, one needs to carefully study how the human body would react to such scaffolds and anticipate several issues such as biocompatibility, anti-microbial mechanisms, immune surveillance and also the potential release of toxic, genotoxic and immunogenic materials.

One way to reach optimal biocompatibility is to design smart and biomimetic materials, which should follow the structure and function of the material for which it aims to 
replace or supplement. ${ }^{[26]}$ In that sense, the interface between local stem cells and the material is a key determinant of both the material and stem cells' fate. ${ }^{[27]}$

Another key factor to successful biocompatibility (i.e., function and survival of the biomaterial) is to design materials that are likely to trigger controlled immunological outcomes that ultimately serve the desired biomedical application. ${ }^{[28]}$ Such tasks however require a careful understanding of inflammatory and immune responses that would favor the design of immunomodulatory materials, that can be obtained by tuning extracellular matrix components. Implantation of biomaterials is rapidly followed by a chain reaction with activation of coagulation and complement systems, as well as the recruitment of platelets and immune cells (including polymorphonuclear neutrophils, monocytes and resident macrophages). Designing materials that shape specific cell and tissue responses locally and allow, for example, to complete physiological wound healing can control immune reaction. In addition, allowing recruitment of cells, by surface coating that participate in the homeostasis of the targeted tissue is likely to facilitate implantation of the biomaterial. ${ }^{[29]}$ Immune response is further stimulated upon implantation of degradable biomaterials where degradation products are likely to elicit an additional recruitment of immune components. It is therefore essential to design smart biomaterials whose degradation products can be controlled. Along this line, it is essential to control the local and distant dissemination of NPs in the case of nanocomposite scaffolds (NP dissemination to be expanded). Indeed, when the NPs are disseminated within the organism after leaking out, one important question is the fate of the NPs within the organism.

\subsection{Fabrication criteria for biomedical applications}

Regarding the fabrication criteria, probably one of the first questions that comes to mind is: do we need a stable or degradable implant over time? This criterion design is crucial in the fabrication of the implantable device and on its functionalization. In the case of long-term implants such as hips, larynx prostheses or endovascular stents, it is quite often difficult to 
bring a flexible solution to render these implants responsive or to formulate it with stimuliresponsive nanocomponents. The main medical issue is to ensure a long term (decade) biocompatible interface.

When the implant is a self-assembled polymer scaffold, it is usually designed to be degradable or resorbable. However, the majority of soft scaffolds are made of synthetic polymers which are not degradable and even if the scaffold can be biochemically disassembled, there is a risk of dissemination or retention of the synthetic polymers in some organs of the body. This approach requires the need for biodegradable polymer structure which can be used as a suture or a sacrificial templating scaffolds for tissue reconstruction. There are some examples of natural or synthesized biodegradable polymers based on poly $(\mathrm{L}-$ lactic acid) (PLLA) and poly(lactide-co-glycolide) (PLGA), whose degradation with time can be tailored with the copolymer composition and chain length. ${ }^{[30]}$ Scaffolds made of proteins, polypeptides or polysaccharides such as dextran or chitosan, which can be colonized by cells and degraded by enzymes, seem to be relevant candidates for such biodegradability and nontoxicity criteria. ${ }^{[31]}$ Some polymer systems are also designed to have an accelerated erosion by using T-degradable polymers which can be useful for a desired remotely controlled degradation. ${ }^{[32]}$ At last, in such architectures the incorporation of heat nanomediators endowed with hyperthermia properties induced by external fields would be helpful to control these degradation profiles.

In addition, interaction of cells and tissues with the scaffold to achieve the efficient scaffold integration in the body, are key issues for fabrication criteria. Bringing optimized mechanical properties is a key point for biomaterial design which should be designed to mimic the tissue and cellular micro-environment (extra cellular matrix denoted ECM). The ideal criteria in terms of mechanical properties for a polymer scaffold are to possess a high mechanical strength combined with a suitable elasticity (high values of elastic modulus) based on non-toxic degradable polymers that can be degraded in a controlled fashion. Furthermore, 
limiting protein adherence is also an important aspect to prevent inflammatory responses, to ensure cell integration. High amounts of water in hydrogels or the chemical functionalization of the scaffold with low fouling polymers allow limited protein adhesion. ${ }^{[33,34]}$

\subsection{Biomedical implementation of the remotely responsive scaffold}

In this section, we discuss the advantages and drawbacks of the potential external fields and the different responsive nanosystems that may be used in the clinics. Major external fields that are useful for biomedical applications are near infra-red (NIR) light, X-Ray, magnetic fields, voltage applied or ultrasonic waves. Even if these stimuli are of different physical natures, the responses from the scaffold-loaded NPs are essentially a local heating, a higher electrical conduction or an actuation effect within the host polymer matrix. Other effects (not detailed in this review), are also reported such as generations of ultra-sound (US) by magnetic NPs ${ }^{[35,36]}$ and also photoacoustic effects upon photo-irradiation of CNTs. ${ }^{[37]}$ Thus, we will first make a brief summary on the different physical behaviors due to the different external stimuli: NIR excitation, alternating magnetic field (AMF), static magnetic field (SMF), X-Ray, US propagation and electroporation $(\mathrm{EP})$.

In the case of NIR excitation, most nanomaterials absorb and scatter light in the NIR region especially designed gold NPs through plasmonic resonance and carbon-graphite structure through vibrational relaxation. Upon NIR irradiation, the excited electrons return back to the ground state by releasing energy as electromagnetic field or heat, and this heating will be called photo induced hyperthermia. The NIR irradiation is a noninvasive and easygoing technology, allowing a controlled and directed excitation (endoscopic excitation of the region of interest). The typical range of excitation goes from 0.2 to $5 \mathrm{~W} / \mathrm{cm}^{2}$ in vivo for 10 minutes on average. ${ }^{[38-41]}$ Nevertheless, this technique suffers from the limited penetration depth due to scattering and absorption of the tissues. Furthermore, the main drawbacks associated with the use of NIR-light responsive nanomaterials such as carbon nanotubes or gold NPs are their non-biodegradability and the need of a careful control of the NIR laser 
light excitation parameters to avoid tissue over-heating that may lead to inflammation or necrosis problems.

The application of a static magnetic field (SMF) in combination with radiofrequency pulses are already commonly used to image soft tissues in the body in magnetic resonance imaging (MRI). An alternating magnetic field (AMF) applied to injected magnetic NPs is also used for magnetic hyperthermia treatment applications. This technology is non-invasive and presents no risks for healthy tissues and total penetration of the full body. The drawbacks are the complexity of use, the cost and the specific implementation for a surgeon. The typical ranges of use in frequency of the magnetic field goes from $100<\mathrm{f}<437 \mathrm{kHz} ; 30<$ time $<60 \mathrm{~min}$; $\mathrm{B}<100 \mathrm{mT} .{ }^{[42,43]}$ Current issues with the use of magnetic nanomaterials as stimuli-responsive systems is that they should be as least cytotoxic as possible. That's why, even if metallic NPs or cobalt or zinc-doped ferrites would be highly preferred for their high saturation magnetization, they would induce important toxicity because of the release of heavy metals. Iron oxide NPs (IO NPs) appear thus as one of the best magnetic NP candidates for such biomedical issues, as will be detailed in the next paragraph 3.1.

$\mathrm{X}$-Ray irradiation is linked to high energy electromagnetic beam inducing ionization radiation. Thus, heavy metal NPs such as gold NPs will enhance the radiation dose through an increased absorption of X-rays, and this will lead to a subsequent ejection of electrons, known as the Auger cascade. ${ }^{[4-46]}$ This irradiation is noninvasive, penetrates the full body but the main drawbacks include risks for healthy tissues, complexity of use, a high cost and a specific implementation. The typical range of use of this irradiation is $25 \mathrm{~Gy}$ of $6 \mathrm{MeV}$ radiation in the presence of gold NPs.

Ultrasound (US) waves are mainly used to compromise the integrity of drug delivery liposomes. This process is achieved through two distinct pathways. Either by thermal release when the US waves are absorbed by the material or by mechanical disrupter. The mechanical link is due mainly to cavitation, where a compressible fluid is incorporated into the liposome. 
This fluid will then oscillate at the US frequency and depending on the amplitude of these oscillations, it is called stable cavitation which is when the oscillations are below the bubble resonant radius, or inertial cavitation leading to the collapse of the fluid drop. The collapse leads either to sono-chemistry generating high temperatures or to shockwaves where the pressure reaches 10000 atmospheres. This technique is noninvasive, penetrates the full body and presents only moderate risks for healthy tissues, and as a plus it can be combined with imaging. This technique is also well suited for lysosome delivery. The typical acoustic amplitude ranges from less than $\mathrm{mW} / \mathrm{cm}^{2}$ (for inertial cavitation) to several $\mathrm{W} / \mathrm{cm}^{2}$ (heating). The frequency ranges from 0.5 to $1.5 \mathrm{MHz}$ and the duty cycle from 1 to $100 \%$. The exerted pressure varies thus from $100 \mathrm{kPa}$ to $\mathrm{MPa} .^{[47,48]}$

Penultimately, electroporation (EP) is a method suitable to increase the permeability of the cell membrane and thus it allows molecules to enter the so-called permeable cell. Short electrical pulses of high field strength are applied to reach EP achievement. The technique is invasive and mostly used to treat solid tumors. It needs surgery to locate the electrodes close to the tumor and the EP presents risks for the surrounding healthy tissues. The EP is usually reached for a potential of $400 \mathrm{~V}$ and the time varies from 3 to 12 minutes before NPs delivery. ${ }^{[49-51]}$

Finally, each of the external stimuli has its advantages and its drawbacks, depending on the therapeutic action and of the instrumentation and setup used by the clinicians. These features of the different stimuli are summarized in the following table (Table 1).

Table 1. Summary of the pro and cons of external stimuli or fields potentially useful in the clinics

\begin{tabular}{lllll}
\hline $\begin{array}{l}\text { External } \\
\text { stimulus / } \\
\text { Invasiveness }\end{array}$ & Advantages & Drawbacks & Experimental conditions & References \\
\hline $\begin{array}{l}\text { NIR light } \\
\text { Non invasive }\end{array}$ & $\begin{array}{l}\text { Easy to use, } \\
\text { applying laser }\end{array}$ & $\begin{array}{l}\text { Limited } \\
\text { penetration }\end{array}$ & $\begin{array}{l}\text { From } 0.2 \text { to } 5 \mathrm{~W} / \mathrm{cm}^{2} \\
\text { in vivo for } 10 \text { minutes on }\end{array}$ & {$[38,39,41]$} \\
\hline
\end{tabular}




\begin{tabular}{|c|c|c|c|c|}
\hline & $\begin{array}{l}\text { beam } \\
\text { (endoscope, } \\
\text { direct } \\
\text { irradiation) to } \\
\text { the region of } \\
\text { interest }\end{array}$ & $\begin{array}{l}\text { depth into the } \\
\text { tissues. }\end{array}$ & average. & \\
\hline AMF & $\begin{array}{l}\text { No risk for } \\
\text { healthy tissue }\end{array}$ & $\begin{array}{l}\text { Complex to use, } \\
\text { costly, specific }\end{array}$ & $\begin{array}{l}100<\mathrm{f}<437 \mathrm{kHz} \\
30<\mathrm{t}<60 \mathrm{~min}\end{array}$ & {$[42,43,52]$} \\
\hline Non invasive & $\begin{array}{l}\text { Full body } \\
\text { penetration }\end{array}$ & $\begin{array}{l}\text { implementation } \\
\text { for a surgeon }\end{array}$ & $\mathrm{B}<100 \mathrm{mT}$ & \\
\hline $\begin{array}{l}\text { X-Ray } \\
\text { Non invasive }\end{array}$ & $\begin{array}{l}\text { Full body } \\
\text { penetration }\end{array}$ & $\begin{array}{l}\text { Risk for healthy } \\
\text { tissue, complex } \\
\text { to use, costly, } \\
\text { specific } \\
\text { implementation } \\
\text { for a surgeon, }\end{array}$ & $\begin{array}{l}25 \mathrm{~Gy} \text { of } 6 \mathrm{MeV} \text { radiation } \\
\text { in the presence of gold } \\
\text { NPs }\end{array}$ & {$[44-46]$} \\
\hline $\begin{array}{l}\text { US } \\
\text { Non invasive }\end{array}$ & $\begin{array}{l}\text { Full body } \\
\text { penetration } \\
\text { Well suited for } \\
\text { lysosome drug } \\
\text { delivery } \\
\text { Combination } \\
\text { possible with } \\
\text { imaging }\end{array}$ & $\begin{array}{l}\text { Moderate risk } \\
\text { for healthy } \\
\text { tissues }\end{array}$ & $\begin{array}{l}\text { Acoustic amplitude } \\
\text { From } \mathrm{mW} / \mathrm{cm}^{2} \text { (inertial } \\
\text { cavitation) to several } \\
\mathrm{W} / \mathrm{cm} 2 \text { (heating) } \\
\text { Frequency from } 0.5 \text { to } \\
1.5 \mathrm{MHz} \\
\text { Time from minute to hours } \\
\text { Pressure } 100 \mathrm{kPa} \text { to } \mathrm{MPa}\end{array}$ & {$[48,53]$} \\
\hline $\begin{array}{l}\text { EP } \\
\text { Invasive }\end{array}$ & $\begin{array}{l}\text { Local solid } \\
\text { tumor } \\
\text { treatment }\end{array}$ & $\begin{array}{l}\text { Surgery needed, } \\
\text { risk for healthy } \\
\text { tissues. }\end{array}$ & $\begin{array}{l}400 \mathrm{~V} \text { electroporation } \\
\text { using pincher electrodes } \\
\text { The timing of } \\
\text { electroporation was } 3 \text { to } 12 \\
\text { minutes before } \\
\text { nanoparticle treatment }\end{array}$ & {$[49-51]$} \\
\hline
\end{tabular}

\section{From nanoparticles and polymers as building blocks to smart responsive}

\section{nanocomposite scaffolds}

The design of suitable responsive nanocomposite scaffolds for drug delivery and tissue engineering applications requires first a well-controlled chemical design both of the inorganic NPs and the polymer scaffolds. Then, achieving a suitable formulation between the NPs and the polymer scaffold and controlling the response of this smart NP-polymer scaffold upon external stimuli (magnetic, electric fields or light) are also key issues to control the scaffold biomedical function (drug delivery or cell actuation/guidance) once implanted within the body. To perform such tasks, the development of smart nanocomposite scaffold relies both on a great understanding of the NPs synthesis and their properties and on a great knowledge in the 
chemical design of polymer assemblies such as hydrogels or polymer ELS fibers. Nevertheless, combined strategies are being developed to give the advantageous features of both the polymer scaffold and of the NPs, but such strategies are various and complex, and according to the process used, they have their pros and cons which are highlighted in this section.

\subsection{Inorganic nanomaterials as ideal building blocks for signal conversion}

In this section, we describe in detail the design of nanomaterials having a remote response under external stimuli that can be incorporated in a polymer matrix for biomedical applications. The main advantage of such nanocomponents, is that they convert one physical signal into another. Thus, understanding the structure and properties of inorganic NPs is of paramount importance to control the NPs response upon external stimuli and then to obtain the desired remote response of the scaffold once the smart device is implanted in a human body.

\subsubsection{Iron oxide NPs and response upon magnetic fields}

Superparamagnetic IO NPs were commercially used as $\mathrm{T}_{2}$ contrast agents for $\mathrm{MRI}^{[54,55]}$ and are also developed for a localized therapy achieved by magnetic hyperthermia $(\mathrm{MH}) .{ }^{[15]}$ The principle of $\mathrm{MH}$ is to submit suspensions of magnetic NPs having suitable magnetic properties to an AMF with given amplitude and frequency. The resulting elevated temperature promotes the selective destruction of abnormal cells (when NPs are internalized into these cells) that are reported to be more thermally sensitive than healthy cells. Moreover, magnetic hyperthermia enhances the sensitivity of tumor cells towards chemo or radiotherapy and was also demonstrated to trigger a thermally-induced release of drugs or to act on cell membranes. ${ }^{[56-58]}$

These NPs release heat locally under such stimulation through three main mechanisms depending on their size: Néel relaxation, Brown relaxation and hysteresis loss. ${ }^{[59,60]}$ Néel and Brow relaxations are the mechanisms reported currently for superparamagnetic NPs ${ }^{[61]}$ while 
hysteresis loss (shift of domain walls) ${ }^{[62]}$ concerns multi-domain particles which display larger sizes than monodomain superparamagnetic NPs. Néel and Brown relaxation mechanisms depend mainly on: the magnetocrystalline anisotropy (i.e. a favored orientation of the NP magnetic moment), the NP volume and the viscosity of the surrounding media. Brownian relaxation will be typically predominant with bigger size magnetic NPs and lower viscosities whereas the Néel relaxation will dominate for smaller size NPs and in media having higher viscosities. The interest of superparamagnetic NPs is that they easily form stable colloidal suspensions due to their superparamagnetic properties and absorb much more power at clinically recommended magnetic fields and frequencies. It is indeed important to adjust the parameters of the magnetic field applied as for a clinically safe application of MH therapy, the product of the frequency and the amplitude of the magnetic field $\left(\mathrm{H}^{*} \mathrm{f}\right)$ should not be higher than $5 \times 10^{9} \mathrm{~A} \mathrm{~m}^{-1} \mathrm{~s}^{-1} \cdot{ }^{[63,64]}$

The positive results obtained by a German company MagForce Nanotechnology (hospital Charité in Berlin) ${ }^{[65-67]}$ by using MH combined with drug delivery for cancer treatment demonstrated the potential of magnetic NPs for such therapy. Furthermore, MagForce obtained $35 \mathrm{M} €$ from the European Investment bank to develop MH. Nevertheless, currently the low heating power of usual magnetic NPs makes that large amounts of NPs are injected locally for MH treatment and these NPs have to be further eliminated by the body. Therefore most works currently are aiming at increasing the heating power of individual superparamagnetic NPs. ${ }^{[68-70]}$

The heating performance is usually assessed by measuring the specific absorption rate (SAR), named also specific loss power (SLP), which is the power dissipated by magnetic NPs per unit of mass $(\mathrm{Wg}-1) .{ }^{[71,72]} \mathrm{SAR}=\mathrm{C} / \mathrm{m} * \mathrm{dT} / \mathrm{dt}$ with $\mathrm{C}$, the water specific heat per unit of volume $\left(\mathrm{J} \mathrm{K}^{-1} \mathrm{~L}^{-1}\right)$, $\mathrm{m}$ the iron massic concentration in suspension $(\mathrm{Fe} \mathrm{g} / \mathrm{L})$ and $\mathrm{dT} / \mathrm{dt}$ the initial increase in measured temperature (initial slope of the heating curve). The term Specific Loss Power is considered as more accurate than Specific Absorption Rate since it figures out better 
the idea of a stored magnetic power released into a thermal power. SAR or SLP (in W/g) values are highly dependent of the intrinsic features of the NPs (structure and composition) and also on extrinsic parameters such as the frequency (f) and the amplitude of the magnetic field $(\mathrm{H}){ }^{[15]}$ For superparamagnetic NPs, SAR/SLP values usually increase with the frequency or the magnetic field amplitude applied. A standardization protocol has been proposed very recently for determining accurate, reliable and reproducible SLP values, thus adequately evaluating the NPs potential. ${ }^{[73]}$

To envision a clinical translation of $\mathrm{MH}$ as therapeutic treatment, magnetic NPs have to be designed in order to obtain the highest SAR/SLP values which should allow to administer the lowest NPs dose at clinically safe low frequency and amplitude of the magnetic field applied. ${ }^{[61,74]}$ The level of heat released by NPs is highly dependent on their structural and magnetic properties (high Ms and high magnetocrystalline anisotropy) ${ }^{[75-78]}$ and first works revealed that iron oxide NPs with a spherical shape and a mean diameter in the range 12-20 $\mathrm{nm}$ are clinically suitable for MH therapy. ${ }^{[79]}$ Thus, synthesis methods of iron oxide $\mathrm{NPs}^{[80]}$ were deeply investigated to improve the MH performance of NPs. The magnetic properties of NPs have been optimized by tuning mainly their shape and their composition (doped iron oxide or core-shell structures). Among synthesis methods, the thermal decomposition method $^{[81,82]}$ was shown to be particularly suitable for controlling the size, shape and composition of NPs, as well as the polyol method. Thus for example, nanocube iron oxide $\mathrm{NPs}^{[83-85]}$ with an optimal size of $19 \mathrm{~nm}$ were found to have high SAR values $\left(2453 \mathrm{~W} \cdot \mathrm{g}^{-1}\right.$ at $29 \mathrm{kA} \cdot \mathrm{m}^{-1}$ and $\left.520 \mathrm{kHz}\right) .{ }^{[74]}$ Recently, they boosted the heating power of the cubic NPs by doping with cobalt. ${ }^{[86]}$ Core-shell NPs consisting of a core with a high magnetic anisotropy and of a shell with a small magnetic anisotropy displayed a very important antitumor effect induced by $\mathrm{MH} .{ }^{[70]}$ Otherwise when iron oxide NPs with a mean diameter of $\sim 22$ $\mathrm{nm}$ coated with dendron molecules display a SAR of 120 and $395 \mathrm{~W} \cdot \mathrm{g}^{-1} \mathrm{Fe}$ with a field amplitude of $150 \mathrm{G}\left(12 \mathrm{kA} . \mathrm{m}^{-1}\right)$ and a frequency of $395 \mathrm{kHz}$ and $796 \mathrm{kHz}$ respectively, ${ }^{[87]}$ the 
same NPs coated with a silica shell presented a SAR of 120 and $209 \mathrm{~W} \cdot \mathrm{g}^{-1}$ Fe respectively. ${ }^{[88]}$ Doping of iron oxide with cobalt, zinc or manganese is also a way to improve heating properties. ${ }^{[68,89]}$ However, the possible toxicity of these doping elements has restricted their in vivo development so far. Nano-engineering the shape of iron oxide nanomaterials (Figure 2) is for instance a way to tailor high SAR values and it allows the use of less cytotoxic magnetic NPs. ${ }^{[87]}$

The heating efficiency of an ensemble of magnetic NPs depends not only on the structural and magnetic properties of NPs but also on the magnitude and frequency of the applied magnetic field, the media viscosity and NPs concentration and aggregation state. ${ }^{[90-92]}$ Therefore, IO NPs displaying high heating power are currently available for MH. In addition, current investigations showed that unlike the majority of inorganic NPs, IO NPs can be metabolized by the human body through biodegradation inside the lysosomal compartment over a month of tissue maturation. ${ }^{[93]}$
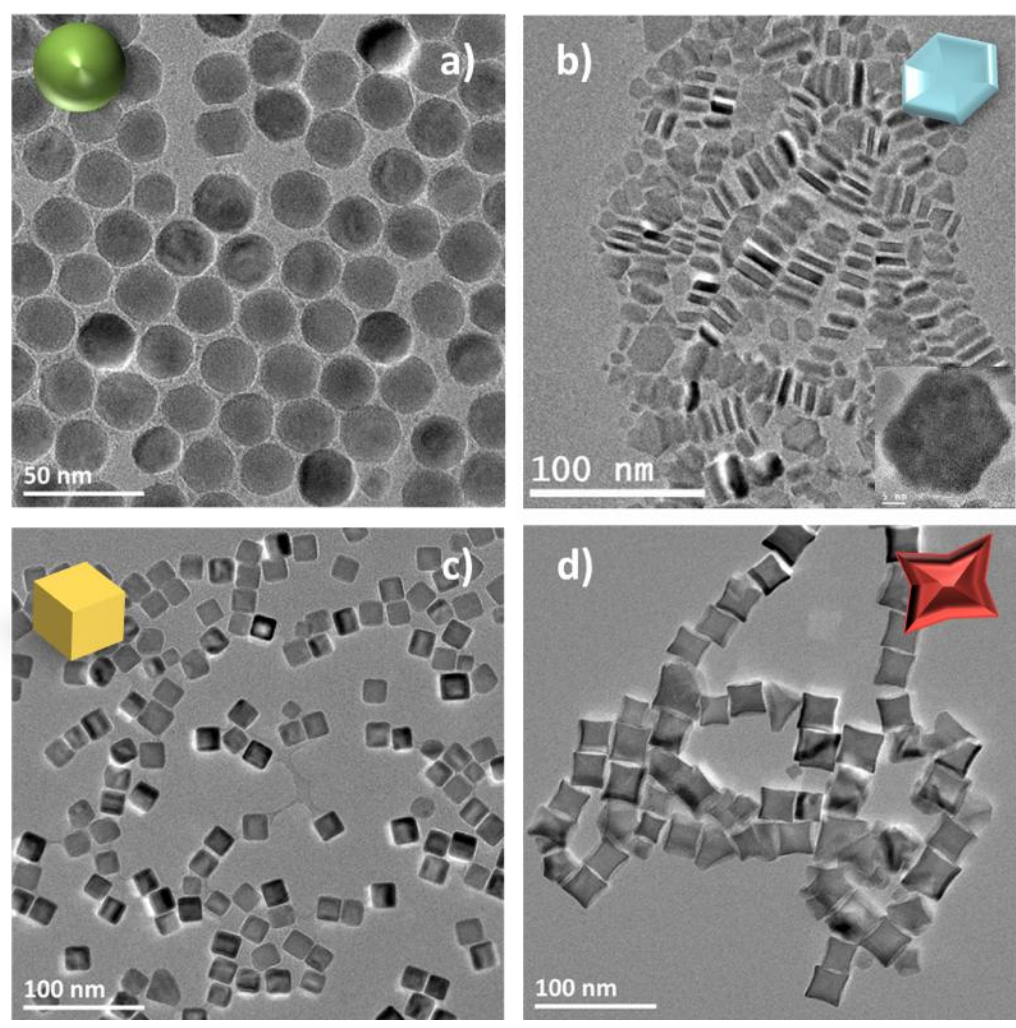
Figure 2. TEM images of a) nanospheres, b) nanoplatelets, c) nanocubes and d) nanooctopods associated respectively to SAR values of $395,177,238$ and $462 \mathrm{~W} . \mathrm{g}-1$ at $\mathrm{f}=795 \mathrm{kHz}$ and H=12 kA m-1. Reproduced with permission. ${ }^{[87]}$ Copyright 2019, IOP Publishing.

\subsubsection{Carbon-based materials and responses under NIR light conversion and electric}

\section{fields}

Carbon nanotubes (CNTs) and graphene have remarkable mechanical, thermal and electron conductivity properties. Especially regarding this latter property, they are relevant key components to develop electrically conductive artificial tissues which allow us to envision many applications for drug release or tissue regeneration. ${ }^{[4,19]}$ However, one first main issue encountered with these carbon based materials is their long dimensions (several tens of microns scale length) which may display similar toxicity to asbestos and thus requires procedures to shorten their dimensions. To solve this problem, CNTs have been treated in a strong oxidizing media under ultrasound to decrease their length and thus their length/diameter ratio. ${ }^{[94]}$ Furthermore, in the last decade, graphene has emerged as an exciting new material. After its first "characterization" following a mechanical exfoliation, ${ }^{[95]}$ the most common approach to achieve graphite exfoliation is the use of strong oxidizing agents to obtain graphene oxide (GO), a more hydrophilic carbon material. ${ }^{[96]}$ Graphene can be also obtained under US in an ammoniac media. ${ }^{[97]}$ More recently another method was developed consisting of exfoliation assisted by US in an organic liquid ${ }^{[98]}$ or with a surfactant in water which allowed obtaining graphene with a high purity. ${ }^{[99]}$

Another main issue with CNTs or graphene surfaces is their hydrophobicity and the need of efficient strategies to cover their surfaces with a hydrophilic coating. There are several strategies with surface chemical modifications to introduce hydrophilic functional (amines, hydroxyls or carboxyls) groups ${ }^{[100,101]}$ and improve dispersions in aqueous media. However, such strategies often require complex procedures, and somehow lack of surface 
density. To improve CNTs dispersions handling and increase the potential for versatile chemical modifications, we have recently proposed the coating of such hydrophobic carbon based materials with mesoporous silica (MS). ${ }^{[102]}$ In this work, a surfactant mediated process for MS coating was achieved on individual sliced CNTs and exfoliated graphene layers. It ensured an efficient separation and dispersion in aqueous media of the CNT and graphene as well as a high antitumor drug loading. We also showed in a parallel study, that this MS layer can be selectively etched from the structure after protein coating allowing the development of a new and alternative method to coat CNTs homogenously with proteins. ${ }^{[103]}$

\subsubsection{Gold NPs for NIR plasmonic and electrical response.}

Gold NPs are also promising theranostic NPs because, when correctly designed, they may provide imaging by NIR fluorescence imaging and therapy through radiosensitization and photothermal therapy. Indeed, due to their unique optical properties and biocompatibility, gold NPs, when irradiated with NIR light, absorb the light and convert it locally into heating. ${ }^{[104]}$ The fact that the NIR light is rather suitable to ensure the lowest absorption and highest penetration depth in biological tissues and to ensure a high local release of heat makes them very promising for photothermal cancer therapy. ${ }^{[105]}$ Some pre-clinical studies have also evidenced the radiosensitizing effect of gold NPs whose presence in tumors has been shown to enhance the efficacy of external radiotherapy. ${ }^{[45]}$ Photothermal ablation is currently clinically developed in USA by the company "Nanospectra Biosciences", and the safety of their gold/silica NPs has been demonstrated. However these interesting properties of gold NPs depend strongly on their size and shape. ${ }^{[106,107]}$

The effect of the gold NPs morphology has been widely investigated and the photothermal properties of gold NPs with different morphology, such as gold nanorods, nanostars, nanorings, nanocages, and hollow nanoshells, have been investigated. ${ }^{[108-111]}$ Nonspherical morphologies were found necessary to observe a suitable effect in NIR region. Nevertheless, spherical NPs with mean size around $15 \mathrm{~nm}$ were found very efficient for 
photothermal therapy because, once gold NPs are internalized in cells, they form selfassembled large clusters directly inside cells, which leads to a surface plasmon resonance shift from the visible to the NIR region. ${ }^{[12,113]}$ This effect was also observed in gold nanoparticles coated with periodic mesoporous organosilica (PMO) as several cores are encapsulated inside the nanoPMOs shell. ${ }^{[114,115]}$ Such gold NPs clusters in the cells ${ }^{[16]}$ were also suggested to result in laser-induced bubble formation that is more effective for eliminating cells. ${ }^{[112]}$

Since only NIR light can penetrate inside living tissues, gold nanoshells, gold nanorods, and gold nanocages which have surface plasmon resonance absorption in the range 650-900 nm are ideal for in vivo imaging or phototherapy. The preparation of gold nanorods with different aspect ratios (length divided by width), which allows tuning their plasmonic absorption peak in the NIR region, is simple and well established. In addition the gold nanorods size is rather small favouring their internalization by cancer cells. ${ }^{[117-119]}$

\subsection{Polymer scaffolds as host integrative matrix}

There are different types of polymer scaffolds that can play the role of the matrix holding the responsive NPs. Such polymeric systems display various physico-chemical features: tunable mechanical stability, elasticity, response to biological media (low adherence, biodegradation), response to thermal changes through T-transitions or T-swelling. In this section, two different types of polymer matrixes, commonly used as scaffolds, are described: hydrogels, and ELS fibers and their features as scaffolds are presented.

\subsubsection{Hydrogels}

A hydrogel corresponds to a hydrophilic 3D polymer network that can swell up to hundreds/thousands of times. There are usually two possible cohesion states in hydrogels held

by chemical or physical crosslinking. ${ }^{[120]}$ Chemical gels are bound by various types of chemical linkages established through covalent crosslinking or polymerization reactions whereas physical gels are usually crosslinked via multiple types of non-covalent interactions 
(H bond-hydrophobic domains, Van der Waals interactions). Chemically-assembled gels are particularly stable as their covalent bonds are resistant to breaking under biological conditions (unless desired) whereas physical gels are usually more prone to be used as resorbable hydrogels. Importantly, one of the most attractive features of polymer hydrogels is that they can be chemically tailored to adjust their physicochemical properties: swelling, mechanical elasticity, molecule diffusion, degradability upon cellular or tissues conditions etc. Indeed, hydrogels can be chemically designed to respond to numerous chemical stimulations: $\mathrm{pH}, \mathrm{T}$ and/or ionic strength. ${ }^{[121,122]}$ Such designs was essentially performed so that they respond to local biological stimuli such as: the acidic $\mathrm{pH}$ of cancer tissues, or the cellular endosomes. Therefore, regarding drug delivery applications, hydrogels scaffolds were used for the release of various products for therapeutic applications. Their cross-linking levels allowed the ability of tuning the porosity and the diffusion of the therapeutics species depending on their size (small molecules, proteins). ${ }^{[123]}$ Another feature of hydrogels for the engineering and industrial process aspects is that they can be molded with any required shape and dimensions. ${ }^{[124]}$

Regarding implantation of the hydrogels, the design of in vivo injectable polymer scaffolds has become an emerging field in this last decade because of their high potential for a range of biomedical applications including regenerative medicine/tissue engineering or drug releasing smart implants. ${ }^{[125-128]}$ Polymer hydrogels are well suited to address the features required for the design of in situ injectable gels which are: i) a stringent biocompatibility as the gel must be non-toxic and non-immunogenic, ii) a rapid in vivo gelation (less than $1 \mathrm{~min}$.) at the injection site at $37{ }^{\circ} \mathrm{C}$, iii) mimicking the complex tissue environment with suitable mechanical properties close to the ECM iv) stability and stiffness over time until potential long-term biodegradation within the body.

In the last few decades, there have been some very interesting approaches of in situ gelling systems by using thermally responsive polyethyleneglycol (PEG), poly(N- 
isopropylacrylamide) (PNIPAM) or Pluronics co-polymers that are solubilized below body T and gelates above the $\mathrm{T}$ threshold. Hence, this strategy may be of interest to solve the problem of direct implantation of the scaffold. Furthermore, as conventional hydrogels, they are obtained though chemical or physical methods i.e. respectively via the formation of covalent or non-covalent bonds. Current chemical methods include either photo-polymerization of preformed acrylate- or methacrylate-modified polymers (PEG, hyaluronic acid, alginate $)^{[129,130]}$ or covalent cross-linking of complementary groups in water-soluble polymers based on various chemistries such as Michael-type additions ${ }^{[131,132]}$ or Schiff's base formation. ${ }^{[133,134]}$ Alternatively, physical gels are obtained through the formation of noncovalent bonds which can be, for instance, of a hydrophobic nature as in the case of thermosensitive polymers including $\operatorname{PNIPAM}^{[135,136]}$ or various block copolymers of $\mathrm{PEG}^{[137,138]}$ which undergo a transition from an hydrophilic state to an hydrophobic state when the temperature reaches the physiological temperature.

\subsubsection{Electrospun fibers}

The ECM of biological tissues (bone, muscle, tendon etc...) is a $3 \mathrm{D}$ fibrous structure with protein-based fibers having an average diameter ranging from a few tens to hundreds of nm. ${ }^{[139]}$ Therefore, the development of scaffolds mimicking the native structure of ECM is of prime importance in tissue engineering in order to favor cell adhesion and proliferation leading to an efficient repair of tissues. ${ }^{[140]}$

Electrospinning has been identified as a process of choice allowing the fabrication of such scaffolds with various polymers. ${ }^{[141]}$ During electrospinning, ${ }^{[142]}$ a polymer solution in a semi-dilute entangled regime is pumped towards a metallic needle which is subjected to an electric field in the order of $1 \mathrm{kV} / \mathrm{cm}$. The charged droplet exiting the needle takes the shape of the so-called Taylor cone from which a jet is propelled towards a collector generally connected to the ground. During its flying, the jet is subjected to vigorous electrohydrodynamic whipping movements allowing an efficient stretching and thus a 
decrease of the jet diameter. At the same time, these whipping movements induce the evaporation of the solvent resulting finally in the pseudo-random deposition of a continuous nanofiber having an average diameter ranging between few tens of nm to few microns as a function of the processing and material parameters. The deposited nanofiber takes the morphology of a non-woven nanofibrous mat also called a scaffold. When decreasing the number of polymer chain entanglements in the solution, the resulting less viscous jet breaks into smaller droplets. Under these conditions, solid microparticles are deposited and the process is named electrospraying. ${ }^{[142]}$

Although electrospinning is a well-known process allowing the fabrication of nonwoven scaffolds, it has been demonstrated that various hierarchically controlled fibrous structures can be obtained ${ }^{[143]}$ such as core-shell nanofibers ${ }^{[144]}$, hairy fibers ${ }^{[145]}$, aligned fibers ${ }^{[146]}$ as well as micro-patterned 3D scaffolds ${ }^{[147]}$ (Figure 3). All these features render the ELS biocompatible materials as promising candidates for various biomedical applications such as biomaterials for tissue engineering ${ }^{[141]}$ and drug delivery purposes. ${ }^{[143]}$ For the latter case, well-designed scaffolds can embed drugs which can be released in a controlled manner. Indeed, the versatility of the process of electrospinning allows the encapsulation of active compounds through diverse strategies such as fiber surface modification, direct electrospinning of the drug within the polymer solution, core-shell electrospinning or electrospraying of drug loaded particles simultaneously with the electrospinning of the scaffold. Depending on the used strategy, the morphology of the scaffold and the kind of processed polymer, different sustained drug release mechanisms can be achieved. ${ }^{[148]}$ 


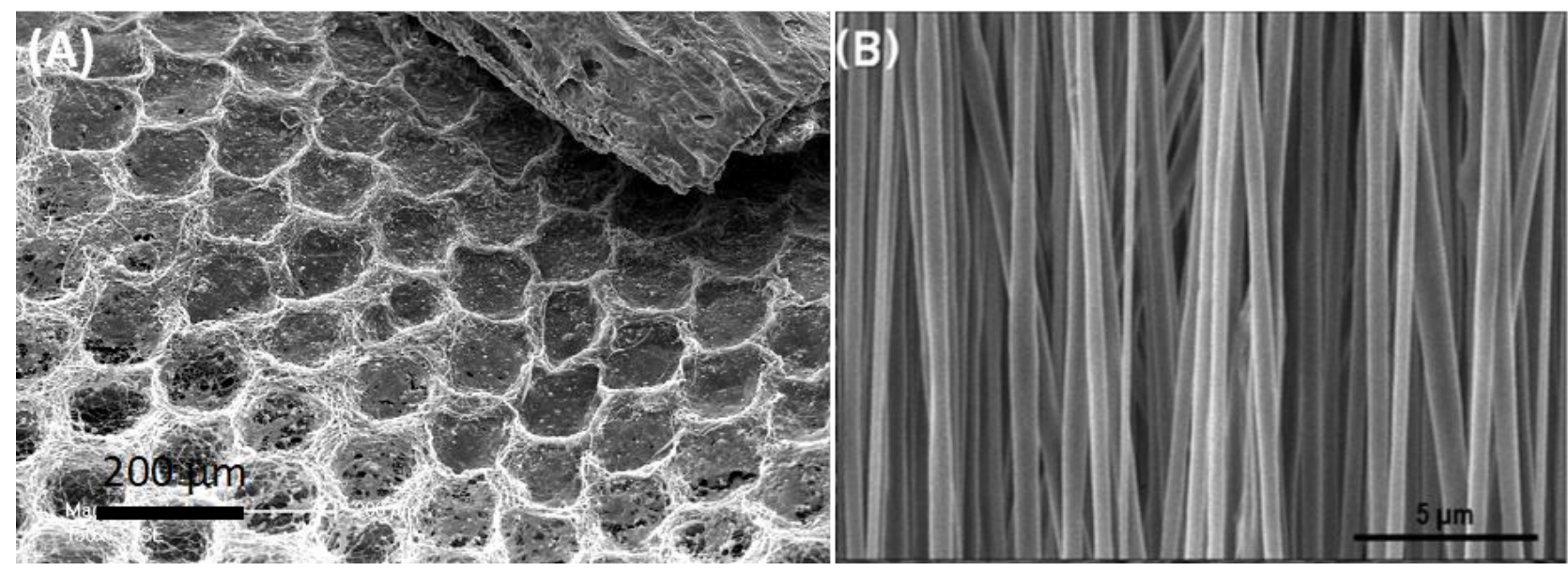

Figure 3. Examples of structured electrospun scaffolds: (A) Organotype culture of cells from a chicken bone embryo onto a honeycomb PCL/Hydroxyapatite ELS scaffold produced by electrospinning/electrospraying onto a micropatterned collector. Reproduced with permission. ${ }^{[149]}$ Copyright 2018, American Chemical Society. (B) Aligned silk fibroin ELS scaffolds obtained by electrospinning onto a rotating collector as synthetic nerve guide. Reproduced under the terms of the CCBY license. ${ }^{[150]}$ Copyright 2018, Holder name.

\subsection{Formulate polymer scaffolds and NPs: process, issues and physico-chemical features}

Another level of functionality can be reached by the combination of responsive NPs with hydrogels or ELS fibers within a polymer composite scaffold. With the aim of obtaining implants that will respond to external stimuli such as NIR light, magnetic field or electric voltage, it is thus of paramount importance to develop powerful processes of scaffold formulations between the polymer and the NPs.

There are different ways to formulate polymer scaffolds and NPs. Various chemical driving forces are involved for the NPs formulation and controlling NPs/polymer interactions is one of the key issues to deal with. It is indeed crucial to chemically tailor the NP surface in order to provide physical or chemical crosslinking of the polymer matrix and obtain a homogeneous NP dispersion while avoiding NP aggregation or leaking. ${ }^{[151,152]}$ In this section, we review the methods allowing the incorporation of different types of inorganic NPs with either hydrogels or ELS fiber scaffolds. 


\subsubsection{Nanocomposite hydrogels}

There are different possible strategies to formulate NPs in a hydrogel polymer scaffold which are respectively:

i) Blending the NPs and the polymer;

ii) Synthesizing the NPs in situ within the polymer scaffold

iii) Grafting covalently the NPs to the surface of the polymer scaffold

i) Blending the NPs and the polymer

The simplest method is probably to blend the NPs suspension in an aqueous solution of the polymer precursor and then trigger the gelation. Gelation can be obtained according to various polymer chemistries (e.g.) polycondensation, photopolymerization, coordination of alginate with calcium forming egg boxes, or via H-bond network formation like in the agarose case.

For instance, in a work by Bannerman et al., ${ }^{[153]}$ the authors synthesized magnetic cryogels by blending poly(vinyl alcohol) (PVA) and magnetic IO NPs through freeze thawing procedures to formulate a fully biocompatible magnetic hydrogel. The NPs can also be dispersed with the monomers and then the polymerization of monomers is induced by different triggers (heat, light induction etc) forming the composite gel. For instance, Frimpong et al. ${ }^{[154]}$ dispersed iron oxide NPs in NIPAM monomer solution and triggered gel formation by radical polymerization. In another example, Servant et al., prepared poly(methacrylic acid) hydrogels loaded with graphene by the in situ polymerization of methacrylic acid. ${ }^{[155]}$ The graphene layers were initially dispersed in water by a ball milling process. However, while the blending technique is particularly simple to proceed, one of the main problems associated with this technique is the difficulty to disperse the NPs homogenously. Some works reported thus the possibility to crystallize the NPs in situ within the polymer scaffolds.

ii) Synthesizing the NPs in situ within the polymer scaffold 
The second method used is an in situ post-synthesis approach where the nucleation of NPs is achieved within a polymer matrix. For instance, Ilg et al., ${ }^{[156]}$ triggered the in situ precipitation of iron salts into IO NPs within the polymer gel. In another work, Wang et al., designed a magnetic composite polymer scaffold by forming a complex between iron (II and III) cations and amine groups of chitosan by increasing the $\mathrm{pH}$ of the scaffold. ${ }^{[157]}$ Similarly, gold NPs can be embedded in gel precursors or grown inside the hydrogel by precipitation of gold salts. ${ }^{[158,159]}$ Here too, such in situ synthesis approaches can display some inconvenience. While the seed nucleation should ensure a homogenously dispersed distribution of NPs, one main issue with such a method is that the reaction conditions of nucleation (basic or reductive) to form the NPs may be too harsh both for the polymer architecture and also for the cells or biological medium that may interact with such structure.

\section{iii) Grafting covalently the NPs to the polymer scaffold}

A third possible approach is the covalent crosslinking by the NPs themselves where NPs act a new points of polymer crosslinking especially in hydrogels. ${ }^{[160]}$ The great advantage of this method is the high chemical and mechanical stability and also the limited leaking out of the NPs. The increase of the mechanical properties is highly needed for biomaterial and regenerative medicine applications. Hence, in a work by Skardal et al., cross-linked thiol functionalized gold NPs in a blended hyaluronic acid/gelatin hydrogel were shown to have a great stiffness as compared to non-cross-linked gold NPs. ${ }^{[161]}$ Carbon-based materials are also particularly suitable nanomaterials to crosslink hydrogels. In a work by Gaharwar et al., the authors investigated the effect on their mechanical properties of the covalent crosslinking of CNTs within a poly(glycerol sebacate) hydrogel. ${ }^{[162]}$ With incorporation of $1 \%$ CNTs followed by covalent crosslinking, the authors measured increased values of the ultimate tensile strength (275 vs $122 \mathrm{kPa}$ ) and of the elastic modulus (1014 vs $198 \mathrm{kPa}$ ) as compared to the poly(glycerol sebacate) hydrogel alone (without CNTs). In another work, covalently crosslinked CNTs - gels were also developed to increase the mechanical properties of gels and 
recreate more rigid tissues. ${ }^{[163,164]}$ Such covalent cross-linking is known also to have an effect over cell interactions with the scaffold surface.

\subsubsection{Nanocomposite ELS fibers}

There are also several possible routes to prepare nanocomposite ELS fibers leading to different locations of the NPs in the scaffold (Figure 4):

i) Blend electrospinning

ii) In situ particle synthesis

iii) Use of simultaneous electrospray and electrospinning

iv) Post-electrospinning impregnation

In the two first strategies, the NPs are distributed inside the fibers. They are thus protected from the environment and consequently, leaking of the NP out of the scaffolds is low. However, their contact with the environment is also limited. Therefore, it would not be the method of choice for chemically triggered drug release, sensing or catalysis for example. In the last two strategies, NPs are either trapped in the ELS matrix during the electrospinning process, physically adsorbed or chemically grafted at the surface of the nanofibers. They will be accessible to the environment but they are more prone to leaching from the fibers.

A)

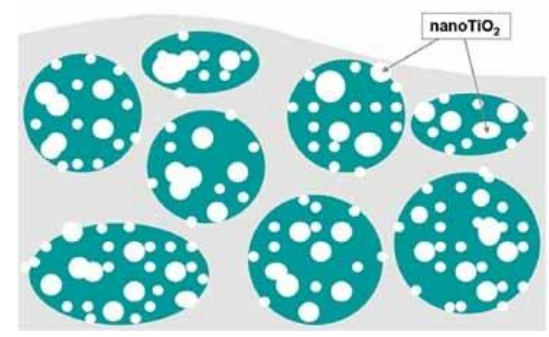

B)

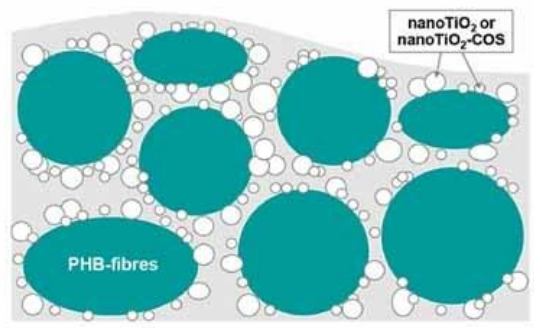

C)

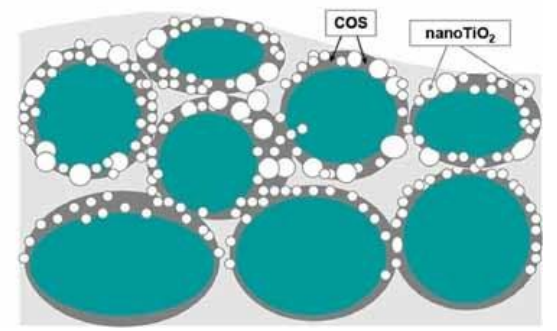

Figure 4. Location of $\mathrm{TiO}_{2} \mathrm{NPs}$ in a poly(3-hydroxybutyrate) (PHB) nanofibrous mat as a function of the following strategies: A) blend electrospinning of the dispersion of nanoTiO $\mathrm{Tin}_{2}$ PHB solution, B) simultaneous electrospinning of a PHB solution and electrospray of a nanoTiO 2 or nanoTiO 2 -COS (chitosan oligomer) suspension. C) post-electrospinning 
impregnation of the $\mathrm{PHB}$ nanofibers in a nanoTiO $2-\mathrm{COS}$ suspension. Reproduced with permission. ${ }^{[165]}$ Copyright 2013, Wiley.

\section{i) Blend electrospinning}

Blend electrospinning is the easier way to obtain NP/polymer composite scaffold. The preprepared NPs are simply dispersed in the polymer solution prior to electrospinning. They are thus distributed in the whole nanofiber section. If the nanofiber is not degradable, the NP should not leach out of the nanofibers, however, as most of the particles are not on the fiber surface, they are not directly accessible and a drug, released from the NP, still has to diffuse through the polymer matrix before being delivered to the environment. In this strategy the main difficulty is to avoid aggregation or sedimentation of the NP in the polymer solutions prior to electrospinning and ensure an even dispersion in the polymer matrix.

Magnetic IO NPs were electrospun by blending the NP suspension with the polymer solution prior to electrospinning. ${ }^{[166,167]}$ In order to improve the dispersibility of NPs, Shan $e t$ $a l .{ }^{[168]}$ prepared the $\mathrm{Fe}_{3} \mathrm{O}_{4} \mathrm{NP}$ by co-precipitation in the presence of PLLA. The synthesized PLLA surface-coated NP later electrospun in PLLA solutions were homogeneously distributed along the nanofibers. Coaxial electrospinning was also performed with magnetorheological fluid (MRF) as the core and a poly(ethylene terephthalate) as the shell. ${ }^{[169]}$ IO NPs were still mobile after electrospinning in the MRF encapsulated inside the fibers. Their response to an external magnetic field was thus instantaneous, increasing the mechanical properties of the nanofibers thanks to dipole-dipole interactions between the NPs.

Other types of NPs were also blended to the polymer solutions before electrospinning. For instance, mesoporous silica NPs (MSNPs) loaded with a drug were also electrospun by blend electrospinning with $\operatorname{PLLA}^{[170]}$ or PLGA ${ }^{[171]}$ with concentration of $15 \mathrm{wt} \%$ and $25 \mathrm{wt} \%$, respectively, of well dispersed MSNPs in the final fibers. Another example is the preparation of gold NP-poly(ethylene oxide) (PEO) composite scaffolds by blend electrospinning. ${ }^{[172]}$ 
Finally, graphene oxide (GO) was also incorporated into PVA ${ }^{[173]}$ or PLGA ${ }^{[174]}$ with the effect of improving the mechanical properties and protein adsorption ability of the fibrous mat.

ii) In-situ nanoparticle synthesis

Metallic salts can be included in the polymer solutions prior to electrospinning and reduced in NPs in situ just before or after the electrospinning step. The size of the NPs and their uniform dispersion of the NPs in the polymer matrix is one of the major challenges of this process. Gold NPs were reduced in situ by addition of tea polyphenol to a polyacrylonitrile (PAN) solution in DMF, just prior to electrospinning. The authors showed that the PAN played the role of a stabilizer through the chelating effect between gold and the cyano groups, allowing the production of well dispersed gold NPs with smaller NPs sizes, as when the gold NPs are synthesized by addition of tea polyphenol in water. ${ }^{[175]}$ In a similar manner, Celebioglu et $a l .{ }^{[176]}$ have prepared PVA nanofibers containing silver NPs by in situ reduction of $\mathrm{AgNO}_{3}$ directly by the PVA, used as reducing agent, prior to electrospinning. They obtained $8 \pm 0.5 \mathrm{~nm}$ NPs but observed some aggregation. Addition of 7.5 to $25 \mathrm{wt} \%$ of hydroxypropyl$\beta$-cyclodextrin $(\mathrm{HP} \beta \mathrm{CD})$ in the formulation, as reducing and stabilizing agent, allowed them to control the size and the dispersion of the silver NPs in the fibers. In the presence of HP $\beta C D$ well dispersed particles as small as $1.8 \pm 0.4 \mathrm{~nm}$ were obtained. These composite nanofibrous mats have also shown interesting antibacterial properties.

In another example, in situ synthesis of magnetic IO NPs was conducted by adding a 2:1 molar ratio of ferric and ferrous chloride to an aqueous PEO or poly(vinyl pyrrolidone) (PVP) solution containing sodium borohydride to reduce the ions to NPs. Electrospinning was performed directly after the NPs synthesis to obtain composite polymer/magnetite nanofibers. Smaller magnetite NPs of $10 \pm 4 \mathrm{~nm}$ were obtained in PVP, probably due to the stabilizing effect of PVP for the NPs as compared to $27 \pm 4 \mathrm{~nm}$ in the PEO fibers. ${ }^{[177]}$

iii) Simultaneous electrospraying and electrospinning 
Electrospinning and electrospraying can be performed simultaneously ${ }^{[178]}$ from both sides of a rotating collector, or in alternating layers ${ }^{[179]}$ leading to a composite fibrous scaffold with particles trapped in it. For example, electrically conductive composite CNT/polyurethane (PU) nanofibrous scaffolds for cardiac tissue engineering were developed by simultaneous electrospray of multiwall carbon nanotubes and electrospinning of PU nanofibers. ${ }^{[180]}$ The CNT adhered on the PU nanofibers forming an interconnected electrically conductive weblike structure with increased mechanical properties as compared to the pure PU nanofibrous mats. Finally, alternating electrospinning and electrospraying on a microstructured collector also allows the control of the localization of the NPs in the scaffolds by the Electrostatic Template-Assisted Deposition (ETAD) of NPs on ELS fibers. This technique was developed by Nedjari et al. ${ }^{[181]}$ who prepared microstructured hydroxyapatite-poly( $\varepsilon$-caprolactone $)$ (PCL) scaffolds for bone regeneration and could easily be adapted to other kind of NPs.

\section{iv) Post-electrospinning impregnation}

Another method to prepare nanofibrous scaffolds containing NPs is post-electrospinning impregnation. An advantage of this method is that the NPs will be deposited on the surface of the nanofibers and thus, will be in direct contact with the environment. However, it may also lead to leaching during use.

Superparamagnetic $\mathrm{Fe}_{3} \mathrm{O}_{4}$ NPs were assembled at the surface of ELS polyurethane (PU) fibers by simply dipping into a NP colloidal suspension in the presence of ethylene glycol. The interactions between the NPs and the PU fibers are very strong, probably due to hydrogen bonding between the amide groups of the PU backbone and the hydroxyl groups capped on the surface of the superparamagnetic NPs. ${ }^{[182]}$

This method can also be used for the preparation of metallic NPs. For example, silver NPs containing nanofibers were also obtained by dipping of poly(acrylic acid) (PAA)/PVA crosslinked ELS nanofibers in $\mathrm{AgNO}_{3}$ aqueous solution enabling the complexation of the $\mathrm{Ag}^{+}$ ions by the carboxylic acid groups of PAA chains. The nanofibrous mats are then immersed 
for 30 min in a sodium borohydride $\left(\mathrm{NaBH}_{4}\right)$ solution to reduce the ions in $\mathrm{Ag}^{0} \mathrm{NPs}{ }^{[183]} \mathrm{The}$ same group also prepared $\mathrm{Fe}^{0} \mathrm{NP} / \mathrm{PAA} / \mathrm{PVA}$ composite nanofibers using the same method. ${ }^{[184]}$ In a similar manner, gold NPs were also attached to the surface of ELS fibers using Layer by Layer (LbL) deposition of 10 bilayers of lysozyme and tannic acid, followed by impregnation of the scaffolds in chloroauric acid solution and in situ reduction to gold NPs by the tannic acid present in the $\mathrm{LbL}^{[185]}$

\section{Applications of nanocomposite scaffolds for controlled drug delivery}

Probably one of the great advantages to use remote action by external stimuli (magnetic, electric fields or light) over other local mechanisms of release ( $\mathrm{pH}$, local etc) is the possibility to perform "on-demand" pulsatile release which ensures the drug to be dosed spatially and temporally. Usual release methods involve the high diffusion of the drugs as a burst release and this approach of remote pulsatile release may be more efficient in future applications to envision long term controlled drug delivery. Here, in this paragraph, we review the possibility of drug releases based on the ability of the polymer scaffold to respond to SMF, AMF, NIR light or electric field (voltage). The examples presented in this section are mainly based on hydrogels and on ELS fibers.

\subsection{Drug delivery upon static magnetic field by magnetomechanical effects}

\section{i) Magnetic guiding of anticancer drugs under SMF field}

The transport of an anticancer molecule loaded within magnetic microgels is a concept that was developed since the early 1980s. For instance, Chen et al. achieved the guiding of magnetic PVP hydrogel microparticles (c.a. 1 micron size) called ferrogel with a magnet for their retention in a rabbit tumor. ${ }^{[186]}$ The ferrogel was loaded with an antitumoral drug, bleomycin A5 hydrochloride (BLM), and was injected intra-arterially. A $0.5 \mathrm{~T}$ magnet was placed at the tumor location for $24 \mathrm{~h}$ and the microparticles accumulated there magnetically. This approach showed a drastic tumor size reduction over 2 weeks as compared to the tumor without treatment. Even in this work, both the treatment with free BLM and the guided 
ferrogel led to an efficient tumor reduction, it shows that the concept of the magnetic guiding in vivo is working, which could be interesting to reduce secondary effects by treating the tumor locally.

\section{ii) Scaffold with remote controlled release of antitumor drugs under SMF applied}

Besides the magnetically induced transport of the magnetic carriers, the application of a SMF (or DC magnetic field) is also a way to act mechanically on a magnetic ferrogel and to trigger therapeutic agent diffusion. In a work by Zhao et al. ${ }^{[6]}$ alginate based ferrogels incorporating $\mathrm{Fe}_{3} \mathrm{O}_{4}$ NPs were shown to be efficient for the release of various therapeutics (mitoxantrone, plasmid DNA, and SDF-1 $\alpha$, a chemokine) in vitro under SMF (Figure 5, left). Under the magnetic field applied, the magnetic ferrogel is submitted to large deformation (over $70 \%$ of its initial dimensions) which generates a water flow through the gel and thus drug diffusion. The gel was stimulated 2 minutes every 30 minutes or $2 \mathrm{~h}$ (depending on the agent used) and the drug release profiles showed a well-controlled release achieved specifically when the magnetic field is applied. Additionally, such a powerful strategy was applied successfully for the controlled delivery of mouse mesenchymal stem cells in vitro and in vivo. (Figure 5, right).

Conversely, the application of a SMF can help also to block drug diffusion by magnetically shrinking the hydrogel. Hence, Liu et al. developed a PVA/IO NPs hydrogel nanocomposite whereupon when a DC magnetic field was applied, the magnetic NPs come closer in space, reversibly aggregate and retain the embedded drugs within the gel by blocking drug diffusion. ${ }^{[187,188]}$ Once the field is removed, the diffusion of the drug restarts out of the gel. The specificity of this system over other sources of external stimuli is that a SMF is required to block the drug diffusion whereas usually the drug is released upon application of an external stimulus. 

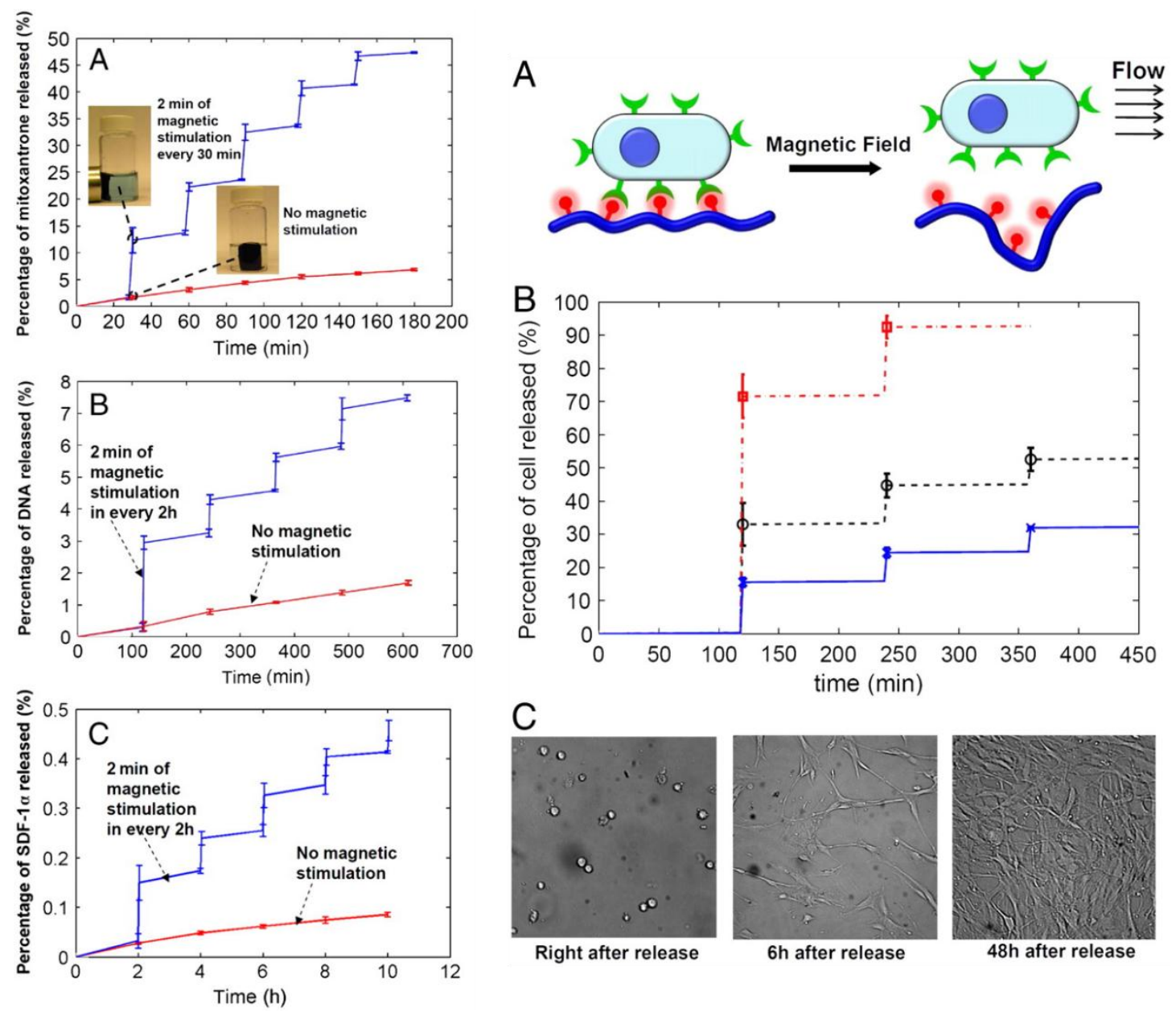

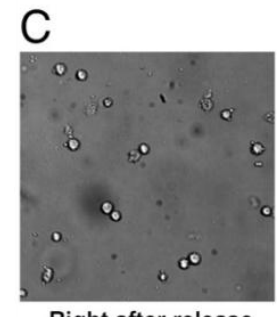

Right after release

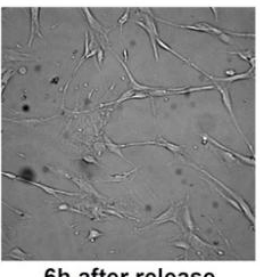

$6 \mathrm{~h}$ after release

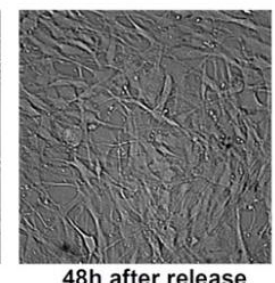

$48 \mathrm{~h}$ after release

Figure 5. At the left. Graphs showing the cumulative release profiles of various therapeutics (A) mitoxantrone, (B) plasmid DNA, and (C) the chemokine SDF-1 $\alpha$ under SMF. At the right A) scheme of the cell release upon DC field from the macroporous gel, B) graphs showing the $\%$ of fibrobast cells release with time and cycled magnetic field application and C) microscopy images showing the proliferation of the cells released with time. Reproduced with permission. ${ }^{[6]}$ Copyright 2011, National Academy of Sciences.

\subsection{Drug delivery upon an alternating magnetic field by magnetothermal effects}

\subsubsection{Magnetothermally induced remote release of molecules under AMF field}

Various works demonstrated the possibility of a controlled pulsatile drug delivery by AMF applied for different applications. Hence, Satarkar et al. investigated the application of a radiofrequency field to a PNIPAM scaffold loaded with magnetic NPs and Vit. B12 as a model drug. ${ }^{[189]}$ The magnetothermal effect resulting from the field application $(300 \mathrm{kHz}, 59.5$ 
kA.m-1) reached the LCST of $32{ }^{\circ} \mathrm{C}$ of the PNIPAM polymer and ensured the release of the Vit. B12 drug by shrinking effect. This effect can be well controlled as demonstrated by the pulsatile release achieved upon cyclic stimulations.

Similarly, Hoare et al. developed biocompatible and biodegradable in situ injectable superparamagnetic IO NPs based PNIPAM hydrogels, made by the condensation of aldehydegrafted dextran with IO NPs functionalized with PNIPAM-hydrazide. ${ }^{[190]}$ The in situ gelation is easy and rapid, and the cross-linking with the magnetic NPs ensured an important increase of the storage modulus (elastic modulus $\geq 60 \mathrm{kPa}$ ). These composite hydrogels were demonstrated to be biocompatible in vitro and in vivo and were loaded with bupivacaine (an anesthetic agent). Controlled pulsatile release of bupivacaine drug could be achieved through application of several pulses of 5 minutes of $\mathrm{AMF}(\mathrm{f}=200 \mathrm{kHz}, \mathrm{I}=30 \mathrm{~A}, \mathrm{P}=1.3 \mathrm{~kW}$ ) leading to a very rapid drug release from the magnetic scaffold. (Figure 6)

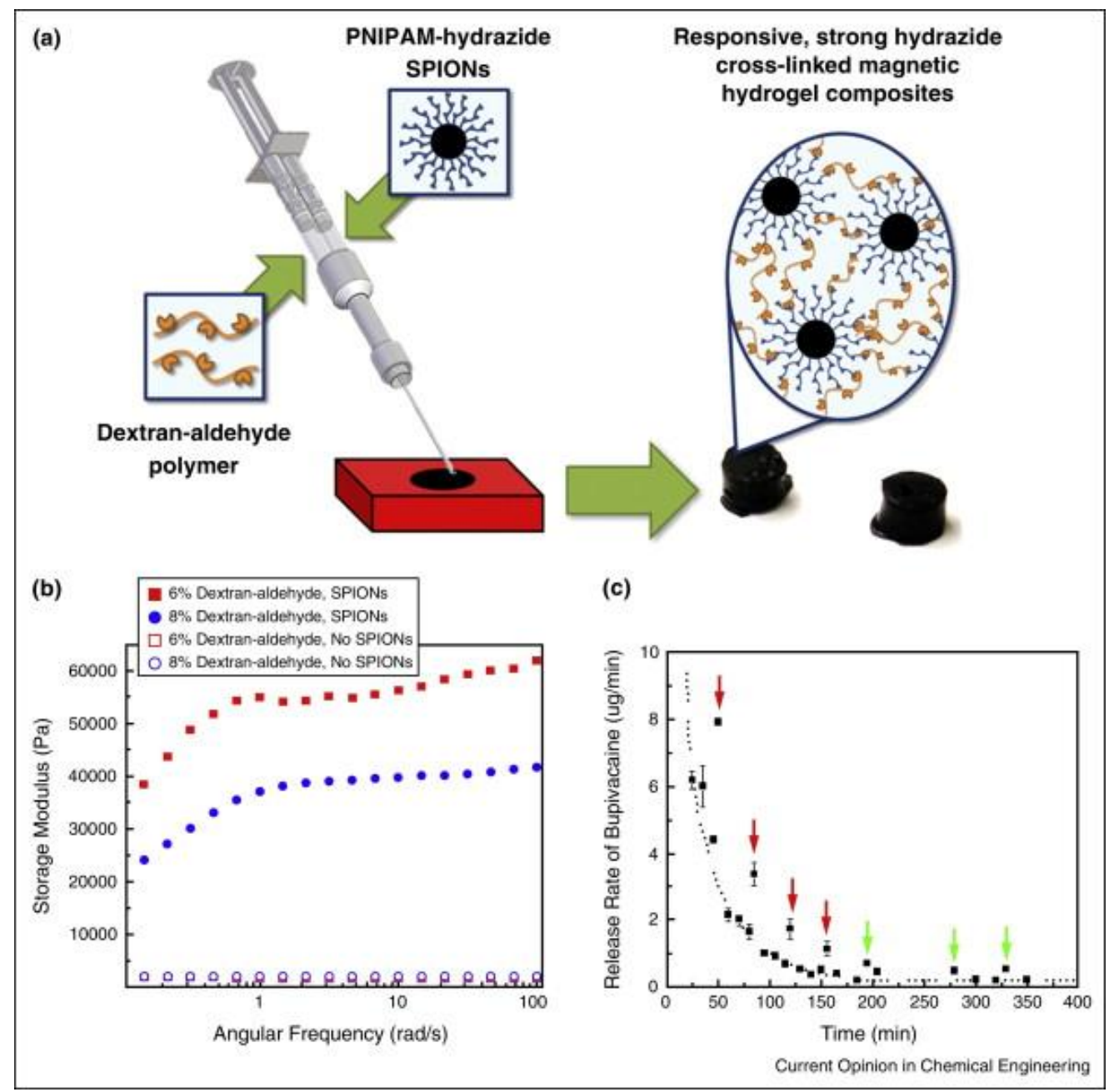


Figure 6. A) Scheme of the biocompatible and biodegradable in situ injectable superparamagnetic IO NPs based PNIPAM hydrogels, made by the condensation of aldehydegrafted dextran with IO NPs functionalized with PNIPAM-hydrazide B) Storage modulus in the presence or in the absence of IO NPs. C) Controlled pulsatile release of bupivacaine through application of 5 minutes pules of $\mathrm{AMF}(\mathrm{f}=200 \mathrm{kHz}, \mathrm{I}=30 \mathrm{~A}, \mathrm{P}=1.3 \mathrm{~kW})$. Reproduced with permission. ${ }^{[1]}$ Copyright 2014, Elsevier.

In a last example, Kim et al. prepared cross-linked PNIPAM ELS nanofibers containing doxorubicin (DOX) and magnetic NPs. ${ }^{[191]}$ The application of an AMF ( $\mathrm{f}=166$ $\mathrm{kHz}, \mathrm{I}=480 \mathrm{~A}, \mathrm{P}=362 \mathrm{~W}$ ) on the electrospun mat containing $31 \%$ of magnetic NPs led to an increase of the fibers temperature from 25 to $45^{\circ} \mathrm{C}$, above the LCST of PNIPAM, resulting in fiber deswelling and release of DOX in the environment. The temperature reached by the magnetothermal effect could be controlled by choosing the appropriate concentration of magnetic NPs in the fibers. Furthermore, swelling and deswelling of the fibers being reversible, on-off switchable release could be obtained.

\section{2 .2 Magnetic hyperthermia therapy combined with magnetothermal drug delivery}

Regarding the potential for biomedical applications and anticancer treatments, the possibility to combine localized hyperthermia and drug delivery was recently achieved from such polymer/NPs composite implants to destroy cancer cells at elevated T above $42{ }^{\circ} \mathrm{C}$. Hence, methacrylate-based PEG magnetic nanocomposites were designed as potential implants for the thermal ablation in cancer treatment along with drug delivery. ${ }^{[192]}$ The authors showed that build-up parameters of the hydrogels such as the ethylene glycol amount and the crosslinking level were determinants for their swelling behavior. Upon AMF, they showed that the iron oxide content and field amplitude influenced the resulting $\mathrm{T}$ profiles and thermal transfers. Regarding tests with healthy and cancer cells, non-cytotoxicity was shown for murine 
fibroblasts in the absence of AMF whereas in the presence of AMF, glioblastoma cells were selectively inhibited.

In another work by Xie et al., injected cross-linked chitosan-PEG hydrogels loaded with IO NPs reduced tumors in mice thanks to a combination of drug release (DOX and docetaxel) and hyperthermia. ${ }^{[193]}$ In this work, the authors used a bi-functional PEG as crosslinkers for chitosan hydrogel matrix and formed a self-healing thermoresponsive scaffold embedded with the two synergic drugs and the magnetic NPs. The nanocomposite hydrogel was shown to be biocompatible and provided a relevant magnetothermal transfer upon AMF. Regarding antitumor action, the authors showed in vitro an important synergistic effect of the three components in combination to kill the breast cancer cell line as compared to one or two components ( 2 drugs or 1 drug and NPs). They also showed a higher antitumor action in mice, where the nanocomposite displayed a better tumor size inhibition as compared to the formulation of one or two components. Noteworthy, such chemothermotherapy effects were also achieved by using the hydrophobic drug paclitaxel as an antitumor drug as described in another work. ${ }^{[194]}$

\subsubsection{Magnetotothermal activation of valves in miniaturized devices}

Another interesting concept that has emerged recently is the possibility to integrate such responsive nanocomposite hydrogels into devices under the form of ultra-thin membranes or within microfluidic miniaturized devices that can both be activated remotely by external fields. Such devices could be used as integrated implants for any drug delivery purposes but also for biosensing applications and the development of lab-on-a-chip devices.

For instance, on-demand drug delivery implants based on PNIPAM magnetic microparticles embedded in an ethylcellulose membrane coated at the surface of a reservoir filled with fluorescein as a drug model were designed to ensure drug diffusion controlled by the AMF ( $\mathrm{f}=220-260 \mathrm{kHz}$ and $\mathrm{H}=0-20 \mathrm{mT}$ ). ${ }^{[195]}$ The temperature increase obtained by the magnetothermal effect was from 37 to $42{ }^{\circ} \mathrm{C}$, but also the sequential and pulsatile delivery of 
fluorescein, were shown to be very well controlled with the AMF sequences. Regarding biological studies, cytotoxicity analysis of the membranes showed a great cell viability with numerous cell lines including fibroblast and mesothelial cells. Furthermore, the membrane was subcutaneously implanted in rats for one and a half months and its heating ability was preserved during this period.

In another work, microfluidic valves activated with a RF magnetic field were designed for lab-on-a-chip applications and for the controlled circulation of fluids. In this work, Satarkar et al., ${ }^{[196]}$ designed a microfluidic device filled with PNIPAM hydrogel having two inputs and one output. The top input was loaded with IO NPs. Upon AMF application ( $\mathrm{f}=300$ $\mathrm{kHz}, 33 \mathrm{kA} . \mathrm{m}^{-1}$ ), the top input generated heat which resulted in the valve opening and then mixing of the two input flows towards the output. The pressure recorded in the top input, indicated the loss of pressure in the channel at each application of the AMF applied.

\subsection{Photoresponsive scaffolds with drug delivery activated by near infra-red light}

As was the case for the magnetically responsive scaffolds in the previous section, light responsive scaffolds are based on the combination of a thermoresponsive polymer scaffold (hydrogel) and NIR light mediators such as carbon-based materials (CNTs or graphene), gold NPs or up-converting NPs. In such constructions, energy conversion occurs upon irradiation with NIR light of the NPs mediators which convert the NIR light into a local heating effect, or into UV-visible photons for up-conversion. The interactions of the NIR light with gold and carbon of various chemical natures are discussed in the section 3 of this review.

\subsubsection{Carbon-based materials}

Carbon based materials such as CNTs, graphene and its derivatives (GO and rGO) are particularly attractive materials incorporated within polymer scaffold for their high capacity of hydrophobic drug loading that may have great interest in various drug delivery applications. ${ }^{[197,198]}$ For instance, in a work by Wu et al. in 2015, GO sheets were combined 
with peptide hydrogels and were stimulated by NIR light to allow pulsatile drug release (Figure 7). ${ }^{[199]}$ The authors showed that the incorporation of the GO sheets into the hierarchically assembled peptide hydrogel brought optimal mechanical properties, handling and facility of injection as compared to the peptide gel itself. Upon NIR light insulation, they showed the controlled pulsatile release of the antitumor drug DOX in vivo.
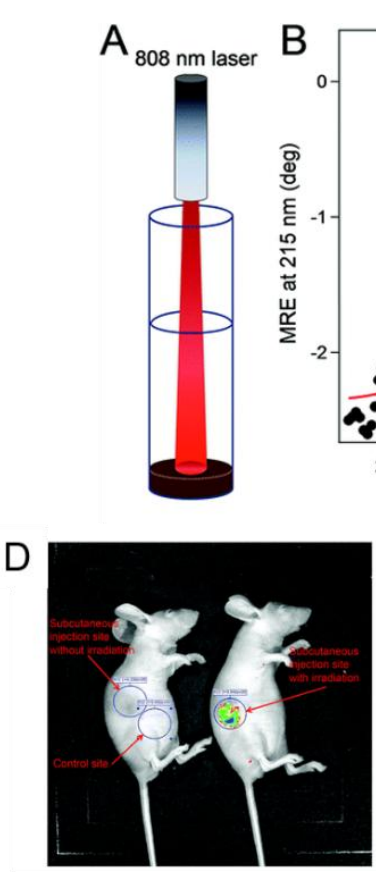
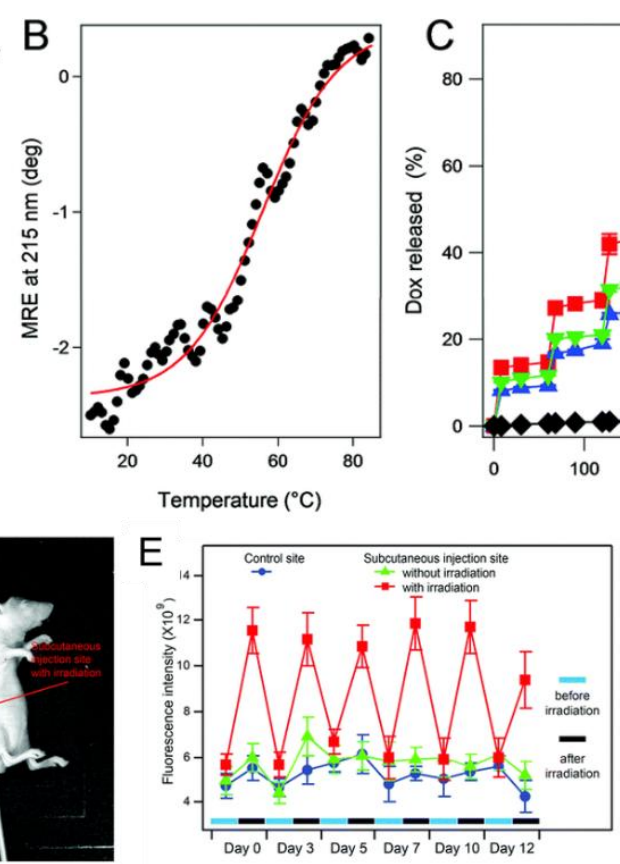
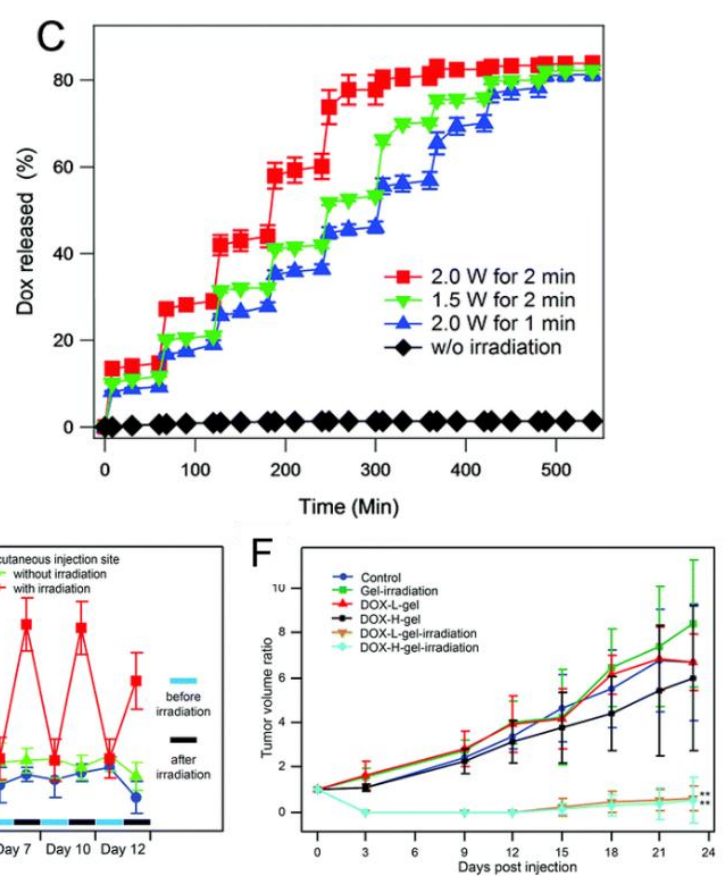

Figure 7. A) Scheme of responsive hybrid hydrogel releasing drugs upon NIR light application $(808 \mathrm{~nm})$. B) Circular dichroism follow-up of the thermal melting of the polypeptide PyGAGAGY. (C) Cumulative release of DOX triggered by NIR Laser at different powers and times. D) DOX loaded hydrogels subcutaneously injected into two mice, with or without irradiation. E) detection of the fluorescence intensities measured from the subcutaneous injection site before and after irradiation over several days. (F) Evolution of the tumor size during treatment. Reproduced with permission. ${ }^{[199]}$ Copyright 2015, Royal Society of Chemistry.

\subsubsection{Gold nanomaterials}


Regarding the application of gold NPs in polymer scaffolds or devices, in a very interesting approach, Sershen et al., developed NIR light activated microfluidic devices with selective photonic responses. In this work, the authors designed a T-shape valve filled in one arm with PNIPAM and gold nanospheres and on the other arm with PNIPAM and gold nanoshells. Both types of gold NPs, given their different NP structures have different plasmonic resonance responses: the nanospheres at $532 \mathrm{~nm}$ and the nanoshells at $832 \mathrm{~nm}$ (Figure 8). The light activation of the valve was specifically dependent on the resonance wavelength of the type of gold NPs used. ${ }^{[200]}$ The same authors showed already in a previous study that PNIPAM/gold nanoshell had also its specific swelling transition at $832 \mathrm{~nm} .^{\text {[201] }}$

A

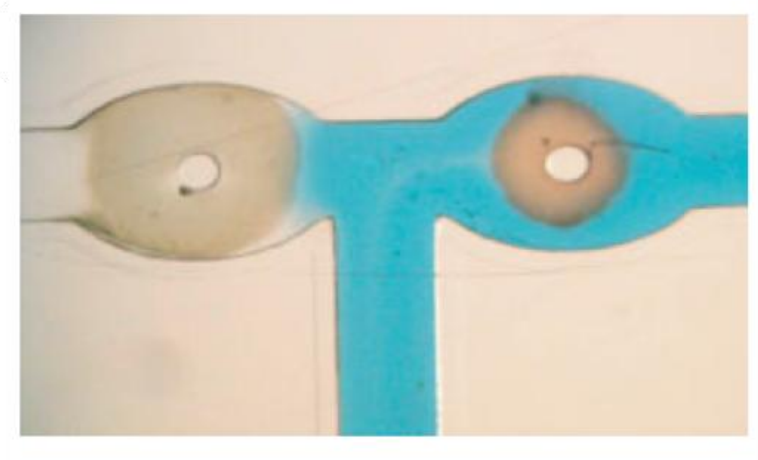

B

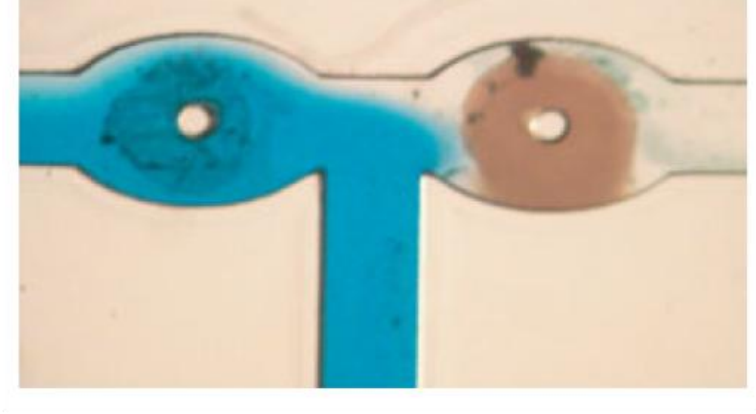

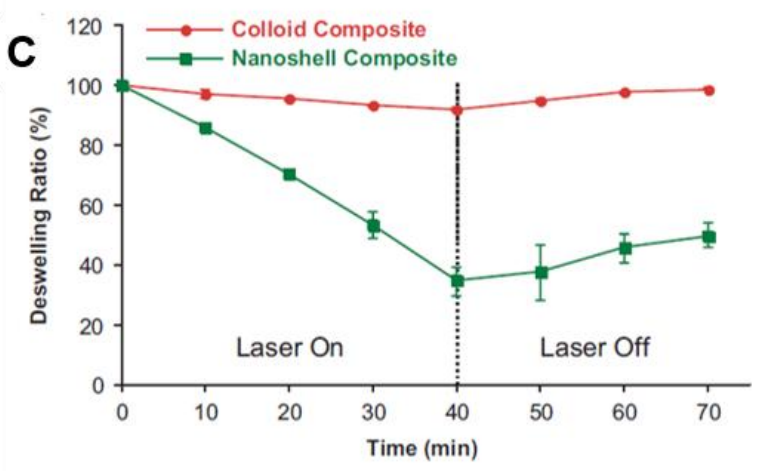

D

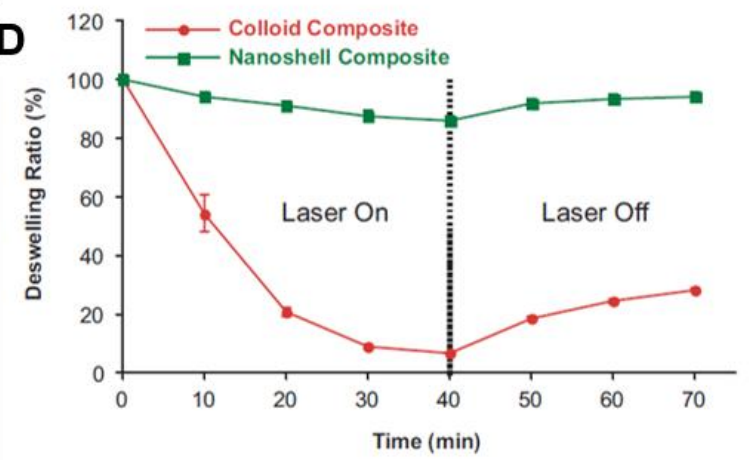

Figure 8. Microfluidic device with two valves. The right one is filled with gold nanospheres while the left one is filled with the gold nanoshells. When the device is irradiated at $532 \mathrm{~nm}$, the right valve opens and when it is irradiated at $832 \mathrm{~nm}$, the left valve opens. Left graphs correspond to the deswelling and the reswelling profiles for the two nanocomposite hydrogels at C) $832 \mathrm{~nm}$ and D) $532 \mathrm{~nm}$. Reproduced with permission. ${ }^{[200]}$ Copyright 2005, Wiley.

\subsubsection{Upconverting materials}


Finally, in another example, NIR light applied to a nanocomposite scaffold was developed to trigger a cascade of photo and chemical processes useful for drug delivery. Hence, Yan et al. developed a photoresponsive hydrogel loaded with lanthanide doped up-converting NPs and the drug. ${ }^{[202]}$ Upon NIR light irradiation $(980 \mathrm{~nm})$, the NP converted this energy into UV light which resulted in the photodegradation of the polymer and then release of the drugs.

\subsection{Electroresponsive scaffolds for transdermal drug delivery}

The design of drug releasing composite scaffolds submitted to electric fields is also highly appealing for biomedical applications. Electrically responsive hydrogels were recently developed especially in the case of transdermal drug delivery which would be a great alternative to drug administration by oral or intravenously injectable routes and where the application of a voltage is technically achievable. Transdermal drug delivery has however several issues given the limited permeability of the skin. Given the possibility of skin electroporation, electrical excitation from a smart scaffold would show great promise to achieve transdermal or subcutaneous controlled drug delivery to the underneath vascular system. ${ }^{[203]}$

Polyelectrolyte based-hydrogels loaded with drugs and submitted to electric fields have been used for these purposes given their mechanical response (bending/deswelling) upon exposure to an electric field. ${ }^{[204]}$ The efficient pulsatile release of drugs can be efficiently achieved using electrical pulses. Various mechanisms allowed the drug delivery, namely: drug ejection by water expulsion, drug diffusion by concentration gradient and also electrophoretic mobility induced by the field between the electrodes if the drug is charged. 


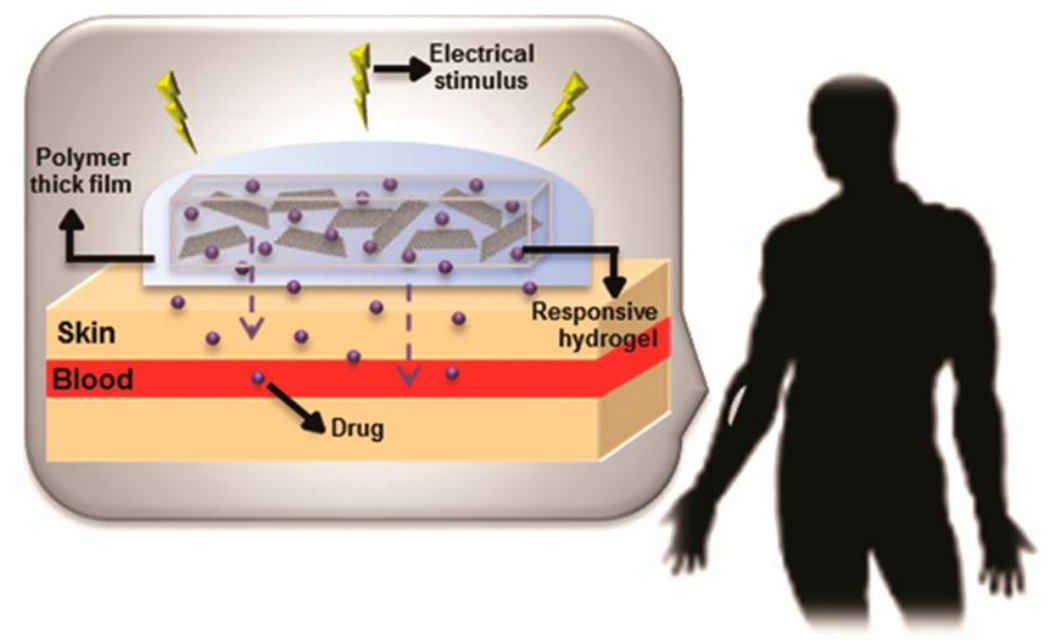

Figure 9. Scheme illustrating the challenges associated with transdermal drug release mediated by an electrically responsive hydrogels incorporated with electrical nanoconductors. Reproduced with permission. ${ }^{[4]}$ Copyright 2015, American Chemical Society.

However, several issues currently limit its use, for instance: gel de-structuration with time, difficult control of drug release and a slow response kinetics. ${ }^{[4]}$ To solve such challenges, some groups have incorporated electrically sensitive NPs into these hydrogels (Figure 9). In a report by Servant et al., ${ }^{[205]}$ MWCNTs were thus dispersed into a poly(methacrylic acid) PMA and permitted to improve the in vivo delivery of radiolabeled sucrose $\left({ }^{14} \mathrm{C}\right)$ used as a model drug upon electrical stimulation. The incorporation of the MWCNTs in addition to improving the mechanical properties of the hydrogel scaffold helped, also helped to lower the voltage and the time applied. In another work by Liu et al., reduced GO was dispersed in a PVA hydrogel for the electrically induced release of the model anesthetic drug lidocaine. Thus, upon electric field application, lidocaine molecules were easily released from the rGO/PVA hydrogels, the amount of released drug increasing with the rGO fraction in the hydrogel. ${ }^{[206]}$

Finally, electrospun PVA/PAA hydrogel nanofibers incorporating MWCNTs were also prepared, allowing the delivery of a high amount of ketoprofen under electric field, thanks to the high surface area of the nanofibers as compared to standard hydrogels. ${ }^{[207]}$

\section{Applications in Tissue Engineering}




\subsection{Bone regeneration}

Polymer scaffolds are particularly well adapted materials for bone regeneration because they allow various simultaneous key cellular functions: cell guiding, proliferation and differentiation. In the bone repair area, magnetic stimulation by external magnetic fields of magnetic NPs embedded in the scaffolds was shown to enhance the osteogenic response of the cells via various mechanisms. ${ }^{[208]}$ Therefore, an increasing amount of smart magnetic scaffolds are being developed to promote bone regeneration processes in combination with an external magnetic field or not.

For instance, Lai et al. have developed composite PLGA-superparamagnetic IO NPs nanofibrous scaffolds by blend electrospinning or by dripping the IO NPs dispersions onto pure PLGA fibers. ${ }^{[166]}$ The obtained scaffolds remained superparamagnetic and contained up to $60 \mathrm{wt} \%$ of IO NPs. In the absence of an external magnetic field, the composite scaffolds could significantly speed osteoblast cells proliferation but did not promote MC3T3-E1 cells differentiation. In order to confirm the role of the magnetic properties of the NPs, Chen et al. have prepared composite PLGA-PCL fibrous scaffold with two types of NPs at their surface, by post-electrospinning layer-by-layer coatings of IO NPs or gold NPs. ${ }^{[209]}$ Both NP coatings increased the hydrophilicity of the fibers and the elastic modulus of the scaffolds, as well as its protein adsorption ability, which resulted in a better adhesion of adipose-derived stem cells (ADSC). More importantly, the IO NPs-coated fibers enhanced the osteogenic differentiation of ADSCs (Figure 10) as compared to gold NPs-coated fibers or nude fibers. According to the authors, this effect could be due to the dense assembly of magnetic particles at the surface of the fibers, leading to phase transition of the magnetism, from superparamagnetism to weak ferromagnetism and acting as a weak internal magnet, which is not the case when NPs are dispersed in the fibers.

The effect of the combination of a SMF with a magnetic scaffold was also studied by Meng et al. who have prepared magnetic NPs/hydroxyapatite/PLA fibrous scaffolds by blend 
electrospinning. They have shown that their composite increased the osteogenic responses of the osteoblast cells under a SMF of 0.9-1 mT. ${ }^{[210]}$ They also implanted their scaffold in vivo in lumbar transverse defects of rabbits. In the presence of an external magnetic field, earlier and faster bone formation was observed in the defect, compared with in its absence. Moreover, the degradation of the scaffold was also faster, probably thanks to the magnetic stimulation of the macrophage recruited at scaffold location. ${ }^{[167]}$ The synergetic effect of magnetic NPs and SMF was also demonstrated by Yun et al., who prepared composite PCL- magnetic NPs porous scaffolds by freeze drying. ${ }^{[211]}$ In vivo, when implanted into mouse calvaria defects, the bone volume was increased by 1.9 times for the scaffold containing $10 \%$ magnetic NPs without SMF and by 2.7 times in the presence of a $15 \mathrm{mT} \mathrm{SMF}$, as compared to the pure PCL scaffold without SMF.

(a)

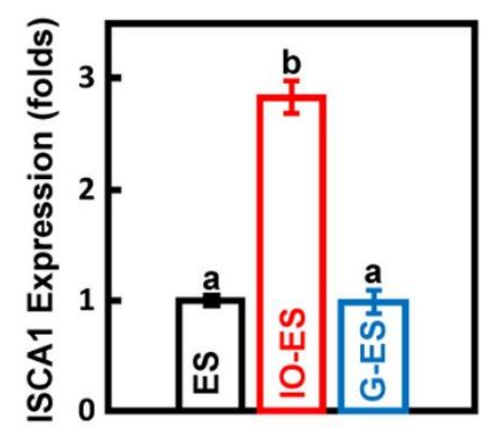

(c) (b)

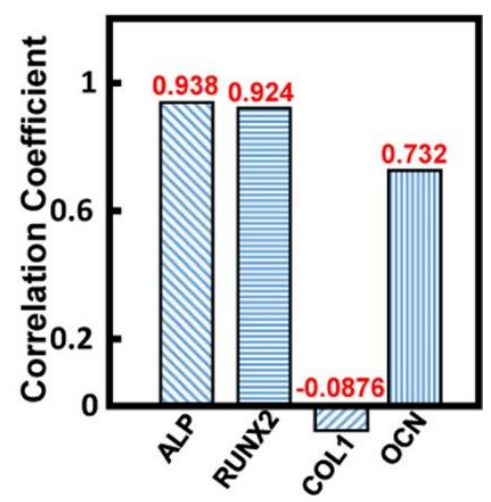

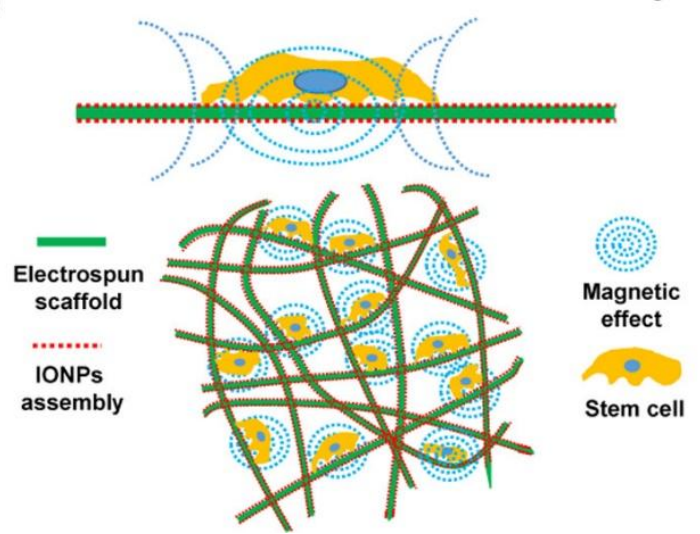

Figure 10. PLGA-PCL magnetic fibrous scaffold obtained, by post-electrospinning layer by layer coating. The application of the magnetic field was shown to enhance the osteogenic differentiation of stem cells. Acronyms: ISCA1, ALP, COL1, RUNX, OCN stand respectively 
for iron-sulfur cluster assembly protein 1; alkaline phosphatase; collagen type 1, runt-related transcription factor and osteocalcin. Reproduced with permission. ${ }^{[209]}$ Copyright 2018, American Chemical Society.

\subsection{Soft actuators controlled by external fields and muscle tissue engineering}

Tissue actuation corresponds to a mechanical motion generated from the nanocomposite scaffold submitted to an external stimulus: magnetic field, electrical voltage etc. Thus, whether by using magnetic NPs with their ability of induced motion upon SMF applied or electrically conductive nanomaterials (carbon-based or gold NPs), their remote effects can be beneficial for muscle cell actuation or contraction. ${ }^{[8,212]}$

\subsubsection{Magnetically actuated scaffolds}

The possibility of magnetically-induced motion by SMF applied, low or high frequency AMF to generate mechanical devices associating strength, flexibility and efficient magnetic response was investigated by researchers these last decennia. Magnetic hydrogels are particularly attractive scaffolds for shape memory which consists of a reversible change in the form of the polymer scaffold induced by the field applied.

Regarding applications by using a SMF, in 2009, the covalent bonding of magnetic metallic cobalt NPs within a poly(2-hydroxyethyl methacrylate) (PHEMA) hydrogels allowed to create nanocomposite hydrogels with a great mechanical stability, and a great flexibility in the shape memory response under SMF. ${ }^{[213]}$ This build-up approach thus combined high saturation magnetization with limited losses of the metal NPs.

Regarding applications by using AMF, in a pioneering work in 1997 , the possibility to lift weights from a PNIPAM ferrogel loaded with maghemite NPs by the application of moderate frequency magnetic field $(2 \mathrm{kHz})$ was investigated. Hysteresis losses from the magnetic NPs submitted to the magnetic field applied controlled the shrinking or swelling with a threshold $\mathrm{T}$ of $34{ }^{\circ} \mathrm{C} .{ }^{[214]}$ Hence, several PNIPAM ferrogel rods having a cross-area of ca. $1.5 \times 10^{-1} \mathrm{~cm}^{2}$ at $22{ }^{\circ} \mathrm{C}$ were shown to reversibly lift up and down $20 \mathrm{~g}$ of weight by 
application/suppression of the magnetic field. This work illustrated the possibility of transduction cascade chain: from magnetic to thermochemical and then to mechanical forces.

Adding magnetic NPs into a thermally responsive polymer material is thus highly attractive as it allows control over the internal motion and thus the memory shape, however it is dependent on diverse synthesis parameters that influence the resulting mechanical or thermochemical properties of the magnetic hydrogel or polymer scaffold. In a study by Yakacki et al., ${ }^{[215]}$ the authors developed methacrylate- based shape- memory polymers by free- radical polymerization having a fixed glass transition temperature $\left(T_{g}\right)$. They investigated both the effects of the amounts of $\mathrm{Fe}_{3} \mathrm{O}_{4} \mathrm{NPs}(0,1$, and $2.5 \mathrm{wt} \%)$ and the degree of chemical cross-linking of the polymer material. They showed that the magnetite NPs reinforcement had an effect on lowering both the glass $\mathrm{T}$ and the strain to failure of the nanocomposite polymer, while increasing the crosslinking level brought a higher resistance to the thermomechanical changes.

\subsubsection{Electrically actuated scaffold for muscle tissue engineering}

Muscles are soft elastomeric tissues composed of actin and myosin filaments displaying contractile motion. This contraction will modify both the morphology and the length of the muscle cells. As seen above in the previous section, the incorporation of carbon-based materials, given their electrical conductivity, help the development of artificial muscles responding with a controlled fashion to electrical solicitations. This last decade, different researchers have investigated the incorporation of CNTs in hydrogels for muscle cell contraction applications. For instance, in a work by Ramon Azcon et al. ${ }^{[216]}$ the authors achieved first a controlled alignment of CNTs in a gelatin methacrylate hydrogel through dielectrophoresis combined with UV polymerization leading to higher electrically conductive and stiffer resulting materials. Then, they showed that the application of an electric field on the CNT-hydrogel was a highly efficient way for controlling the orientation and differentiation of the $\mathrm{C} 2 \mathrm{C} 12$ myoblast cells into contractile myotubes as compared to the non- 
aligned CNTs-hydrogel (Figure 11). Hence, this material showed great potential to develop contractile muscle myofibers.

Regarding light-actuated smart scaffolds, it is worthy to note that they are scarcely investigated. We can cite the example of graphite oxide layers loaded within elastin-like polypeptides $^{[217]}$ displaying a mechanical actuation involving bending, stretching, twisting motions upon NIR light irradiation.

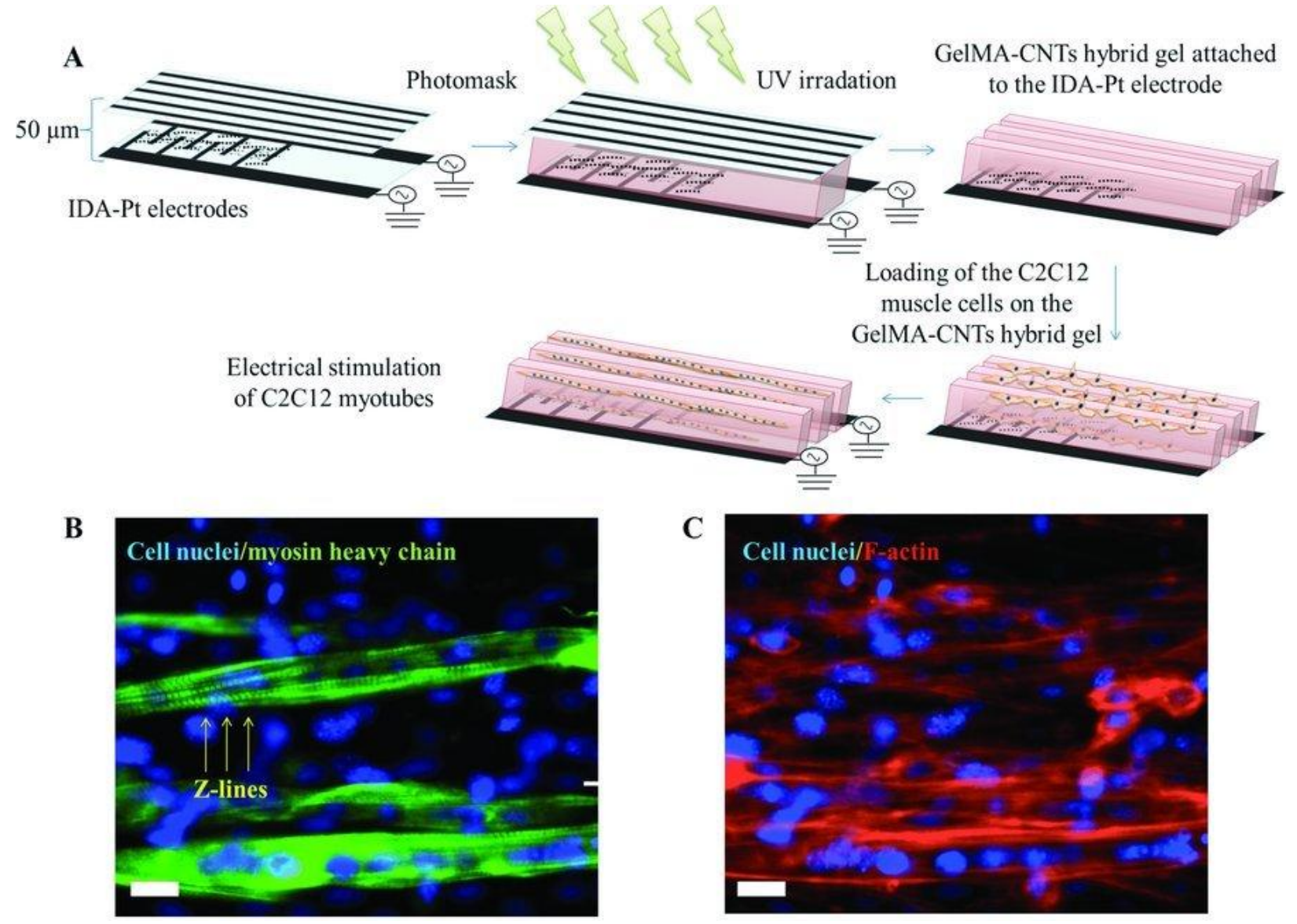

Figure 11. A) Process to design the CNTs aligned within the GelMA Hydrogel and to ensure the differentiation of muscle cells, $\mathrm{C} 2 \mathrm{C} 12$ myoblasts, upon electric field application. B) and C) microscopy images of immunostained cell nuclei/and myosin chains (B) and cell nuclei/ actin filaments (C). Reproduced with permission. ${ }^{[216]}$ Copyright 2013, Wiley.

\subsection{Cardiovascular tissue regeneration induced by external fields}


The development of strategies allowing tissue engineering of cardiac muscles raised a strong interest to fight cardiovascular diseases. Important challenges in the field are the need of prevascularization of cardiac muscles around cardiovascular implants but also the development of new methods to assemble and design new vessel-like architectures. Here too, the use of field responsive nanomaterials may be of interest for the development of cardiovascular tissues.

\subsubsection{Magnetically induced vessel-like structure engineering}

Magnetic scaffolds made of IO NPs and alginate hydrogels were assessed for the cardiac cells stimulation in vitro under magnetic fields. Sapir et al. showed that aortic endothelial cells seeded on such materials and submitted to AMF over 7 days led to the generation of vessellike architectures taking the form of capillary-like structures. This demonstrated the possibility to induce the creation of vascular tissues upon magnetic solicitation. ${ }^{[218]}$

Aside from the magnetic induction of vascular tissues, the assembly of microvascular like architectures under a SMF was also shown as a relevant approach to recreate cardiovascular tissues. Hence, very recently, alginate based-microtubes mimicking tubular vascular tissues, embedded with magnetic NPs in their walls and associated with high-density seeding of NIH/3T3 fibroblasts were recently designed through magnetic guided

assembly. ${ }^{[219]}$ Especially, a suitable surface chemistry of the magnetic alginate fibrous microring fibers allowed cell layers' attachment to the rings and their assembly upon an applied magnetic field.

Other works reported also the combination of different responsive NPs for multimodal excitations (electric field and AMF) with smart scaffolds dedicated for cardiovascular tissue engineering. Hence, Liu et al. reported the fabrication of electrically conductive and magnetically responsive scaffold by incorporating CNTs and IO NPs in an elastin hydrogel scaffold ${ }^{[220]}$ renowned for its excellent viscoelastic properties.

\subsubsection{Electrically actuated scaffolds for heart tissue applications}


Nanocomposites made of hydrogel and CNTs can be also applied as electrically conductive biomaterials for heart tissues applications. For instance, Shin et al. developed methacrylated gelatin (GelMA) hydrogels cross-linked with GelMA coated MWCNTs ${ }^{[221]}$ through photopolymerization, which led to an important increase of the mechanical strength ( 3 times) due to nanoscale fibrous mesh like network. Later on, following this work, the authors showed that cardiomyocytes in contact with the CNTs-GelMA scaffold displayed a 3 fold increase in their beating frequency upon an applied voltage ${ }^{[222]}$ as compared with gels without CNTs. The authors also showed that incorporation of the CNTs allowed a lower voltage to be applied, ensuring the cardiomyocyte cells were beating which was explained obviously by a more electrically conductive network through the CNTs-GelMA as compared to Gel-MA. Cardiac tissue patches were engineered from the CNTs-GelMA surface after seeding cardiac cells on the scaffold. The patch displayed regular mechanical displacements ( $\mathrm{mm}$ to $\mathrm{cm}$ ) with time due to continuous contractions and relaxations.

Aside from carbon-based scaffold materials, gold NPs were also loaded in hydrogel scaffolds with the aim to create engineered scaffolds ensuring electric signal propagation for electrical stimulation of cardiac cells. Hence, in a work by Dvir et al., gold nanowires were formulated inside alginate hydrogel which was shown to be efficient both for cardiomyocyte growth and improvement of the hydrogel mechanical properties. (Figure 12) Neonatal rat cardiomyocytes were interconnected with the conductive nanocomposite hydrogel which acted as a gate to propagate the electrical current. Most importantly, a synchronic contraction of rat cardiomyocytes upon electrical excitation was obtained with gold NPs/alginate hydrogels ${ }^{[223]}$ and an increase of cardiac markers (troponin I and connexin 43) was measured as compared to alginate gels alone. 

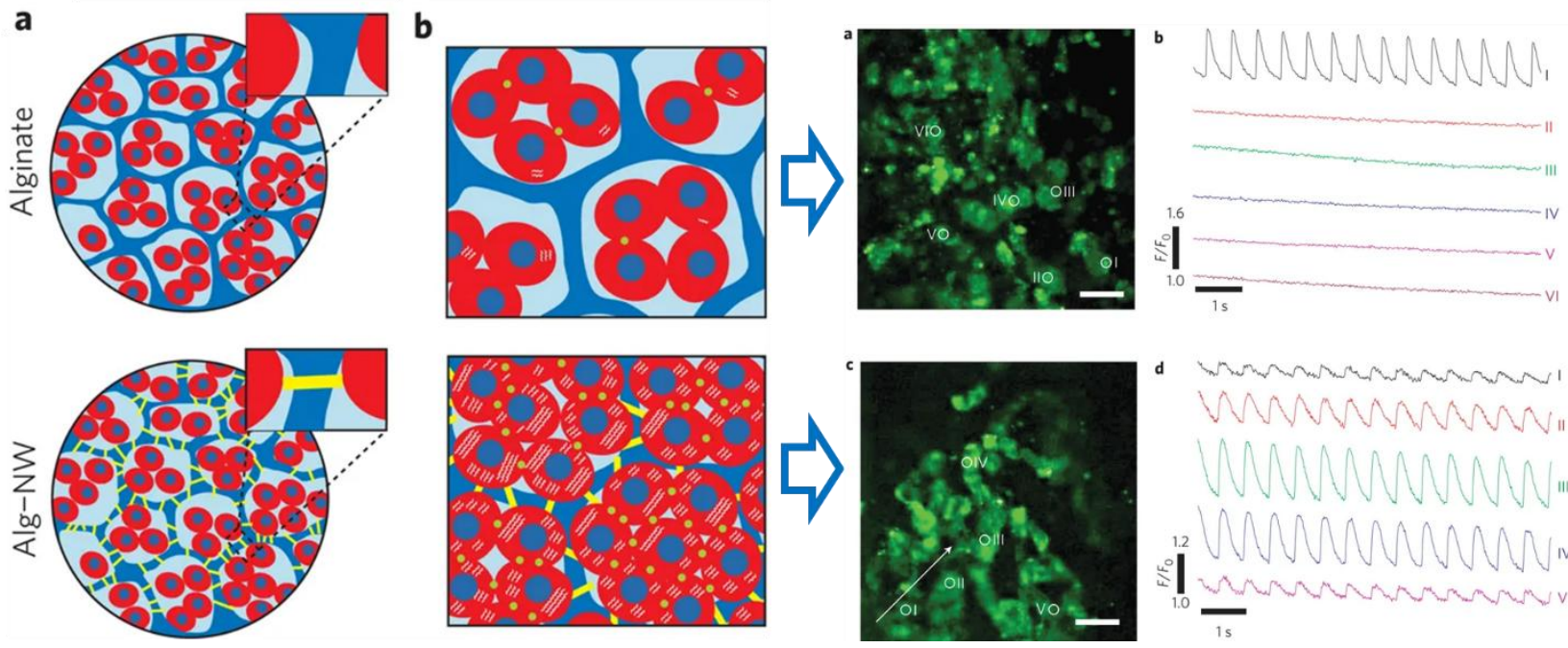

Figure 12. At the left. Scheme showing alginate and alginate-Au nanowires scaffolds seeded with cardiomyocytes for the design of cardiac patches. The cardiomyocytes, alginate network and Au wires are respectively shown in red, blue and yellow. At the right, calcium transients upon electrical stimulation reveal muscle cell contraction and their associated electrical signals in the different locations of the cell tissue, which present a synchronic response. Reproduced with permission. ${ }^{[223]}$ Copyright 2011, Springer.

\subsection{Neuronal regeneration}

Smart scaffolds can be of huge interest in a case of injury axonal development and neuronal cell guiding. Hence, recently, magnetic scaffold presenting aligned collagen fibers were thus designed by the application of a magnetic DC field on a mixed solution containing collagen fibers and iron oxide NPs. These alignment patterns were demonstrated as very useful substrates tools for the directed growth of neuronal cells seeded on the scaffold. ${ }^{[224]}$

\section{Perspectives}

Important challenges are raised in this domain to ensure an ideal in vivo scaffold integration and a remote response remain difficult to achieve. ${ }^{[225-227]}$ Furthermore, in the future, some perspectives are expected from these developments. The list is non-exhaustive and some of these works have been already initiated. However, they represent important perspectives for the development of such smart materials like: i) the remote release of biomolecules for tissue 
engineering applications; ii) the delivery of insulin from implanted scaffolds to treat diabetes or iii) the design of self-degrading and self-healing scaffolds to facilitate biointegration; iv) the design of supra-particulate constructs i.e. self-assembled NPs.

\section{i) Remote release of fragile biomolecules}

The remote release of fragile biomolecules: proteins, DNA, growth factors is a very promising research field, which would be an interesting way to deliver, in a controlled fashion, key biomolecules for tissue engineering applications for instance. Previously, a low frequency magnetic field was already used for actuation of magnetic beads added in ethylene vinyl acetate polymers and this material allowed the release of bovine serum albumin (BSA). ${ }^{[228]}$ In another more recent work, the release of various proteins like insulin, BSA, and lysozyme were assessed by using scaffolds mixing gold NPs + PNIPAM polymer. ${ }^{[229]}$

Scaffolds releasing DNA were also recently reported. For instance, in a work by Miyako et al., CNTs/nanohorns were released from PNIPAM scaffolds upon NIR light insolation at $1064 \mathrm{~nm} \cdot{ }^{[230]}$ Moreover, more recently, in a work by Khademhosseini et al., GO loaded hydrogels made of gelatin methacrylate were shown to deliver DNA plasmid coding for VEGF synthesis. When injected in rats, it favored the cardiac tissue regeneration especially myocardial neovascularization while limiting the fibrosis. ${ }^{[231]}$

\section{ii) The delivery of insulin from implanted scaffold to treat diabetes}

Diabetes concerns currently hundreds of millions of people over the world and is characterized by a lack in the regulation of the glucose level in the blood. This is often due to a lack of insulin, a peptide hormone, which allows control over the glucose levels. Dysfunction of the pancreas in chronic diabetes inhibits the insulin secretion in blood from the Langerhans islets, which implies that the metabolic glucose level in the blood cannot be regulated. ${ }^{[12,232]}$ In seminal works by Kost, Langer et al. (1987) magnetoresponsive matrices were demonstrated as efficient systems to release insulin in diabetic rat models and decreased their glucose levels in the blood. ${ }^{[233]}$ Other works involved the design of alginate gels loaded 
with ferrite microparticles for the triggered delivery of insulin. ${ }^{[234]}$ A recent review by Langer et al. updated this research area and reported that sensing glucose and being able to deliver insulin from such nanocomposite polymer architectures would foster strategies for diabetes treatments.

iii) Self-healing and self-degrading scaffolds

Another topic of interest that should open perspective in the future is the development of scaffolds that have properties for self-action controlled remotely: such as self-healing if the implant may be subject to cracks along its lifetime or self-degradation if the implant is designed to be degradable with time. Hence, in a work by Du et al. ${ }^{[235]}$, switchable tissue adhesion self-healing gels were designed by incorporating CNTs within polyethylene polyamine gels with tunable mechanical properties. The authors showed that adhesion of the scaffold to body tissues could be remotely switched by application of NIR light. The development of magnetic self-healing hydrogels ${ }^{[236,237]}$ is also an elegant way to reversibly control the solid/liquid state of the hydrogel and ensure a suitable injection of the gel in vivo.

Regarding self-degradation scaffolds, there is a need today in the design of polymer scaffolds to render them fully biodegradable and avoid the need for surgery. The remote induced hyperthermia effect generated by activatable NPs may be beneficial to ensure a remote degradation of an implant by playing with the accelerated hydrolysis with $\mathrm{T}$ of some polymers for instance. Hence, degradable implants made of poly(beta-aminoester) presenting hydrolytic degradation profiles with $\mathrm{T}$ were loaded with magnetic NPs and application of an AMF showed a fast degradation rate of the scaffold, ${ }^{[32]}$ which resulted in faster release of encapsulated polyphenols as drug models.

\section{iv) Design of supra-particulate constructs}

At last, the emergence of hybrid nanomaterials with a complex design, may afford progress in the future in this research area. Nano-objects such as spatially controlled supra-particulate constructs $^{[238]}$ could associate different nanomaterials stimulated by different sources. For 
instance, the combination of gold and iron oxide is interesting for dual photo and hyperthermia. ${ }^{[239]}$ Furthermore, metal-organic particles based on metal-organic framework $(\mathrm{MOF})^{[240]}$ or metal-phenolates networks $(\mathrm{MPNs})^{[241]}$ are also relatively new nanomaterials to consider for stimuli responsive effects. To date, MOFs are more used as drug reservoirs coated around responsive cores to achieve drug delivery and phototherapy for cancer therapy. ${ }^{[242-244]}$

\section{Conclusion}

As seen throughout this review article, the combination of externally responsive (magnetic, carbon based materials, gold) NPs with polymer scaffolds affords new structural and physical responsive properties to the nanocomposite scaffold. Hence, they can be designed with a response to multiple stimuli (electric, magnetic field, light, $\mathrm{T}$ etc) and trigger or transduce into chemical or mechanical effects: swelling/release of compounds, change of hydrophilicity/hydrophobicity state. Typically, the property of certain polymer chains to possess a LCST behavior (LCST - transition of the polymer chain from coil to globule) converts a physical stimulus such as NIR light or magnetic field into a local heating that will provoke the effects as described above.

Regarding the chemical design of such materials, the formulation between the NPs and the polymer scaffold is a complex task as it often relies on diverse possibilities of strategies of incorporation: NPs blending, in situ NPs synthesis or NPs covalent crosslinking. Main current issues are to ensure an efficient and homogenous NPs incorporation and to avoid NPs leaking out, or aggregation. To solve this problem, chemists can play with the surface state chemistry of the NPs to ensure optimal formulation. Hence, depending on the targeted application, choosing the right type of NPs in terms of chemical nature, nanostructure, toxicity, surface modification, interactions with the polymer scaffold will be a highly crucial aspect. 
Finally, such approaches should open the way towards the design of new biomaterials and new technological devices interacting remotely and non-invasively by ensuring a therapeutic delivery or biochemical process to the patient and by collecting information/data in real time to the clinicians and biomedical engineers.

\section{Acknowledgements}

D.M. acknowledges the Materials Institute Carnot Alsace (project ProtRemote) and the Canceropôle Est (project VIVIRMAG) for the financial supports. Bing LI would like to thank the Chinese Scholarship Council (CSC) for the grant during her PhD in University of Strasbourg.

Received: ((will be filled in by the editorial staff))

Revised: ((will be filled in by the editorial staff))

Published online: ((will be filled in by the editorial staff))

\section{References}

[1] S. B. Campbell, T. Hoare, Curr. Opin. Chem. Eng. 2014, 4, 1.

[2] A. K. Gaharwar, N. A. Peppas, A. Khademhosseini, Biotechnol. Bioeng. 2014, 111, 441.

[3] A. A. Adedoyin, A. K. Ekenseair, Nano Res. 2018, 11, 5049.

[4] S. Merino, C. Martín, K. Kostarelos, M. Prato, E. Vázquez, ACS Nano 2015, 9, 4686.

[5] S. Talebian, J. Foroughi, S. J. Wade, K. L. Vine, A. Dolatshahi- Pirouz, M. Mehrali, J. Conde, G. G. Wallace, Adv. Mater. 2018, 30, 1706665.

[6] X. Zhao, J. Kim, C. A. Cezar, N. Huebsch, K. Lee, K. Bouhadir, D. J. Mooney, Proc. Natl. Acad. Sci. 2011, 108, 67.

[7] N. S. Satarkar, D. Biswal, J. Z. Hilt, Soft Matter 2010, 6, 2364.

[8] T. Dvir, B. P. Timko, D. S. Kohane, R. Langer, Nat. Nanotechnol. 2011, 6, 13.

[9] P. X. Ma, Adv. Drug Deliv. Rev. 2008, 60, 184.

[10] A. Haider, I.-K. Kang, Preparation of Silver Nanoparticles and Their Industrial and Biomedical Applications: A Comprehensive Review. Adv. Mater. Sci. Eng. 2015.

[11] C. R. Gordijo, K. Koulajian, A. J. Shuhendler, L. D. Bonifacio, H. Y. Huang, S. Chiang, G. A. Ozin, A. Giacca, X. Y. Wu, Adv. Funct. Mater. 2011, 21, 73.

[12] O. Veiseh, B. C. Tang, K. A. Whitehead, D. G. Anderson, R. Langer, Nat. Rev. Drug Discov. 2015, 14,45 .

[13] P. Schexnailder, G. Schmidt, Colloid Polym. Sci. 2009, 287, 1.

[14] A. Vashist, A. Kaushik, A. Ghosal, J. Bala, R. Nikkhah-Moshaie, W. A. Wani, P. Manickam, M. Nair, Gels 2018, 4, 75.

[15] C. Blanco-Andujar, A. Walter, G. Cotin, C. Bordeianu, D. Mertz, D. Felder-Flesch, S. BeginColin, Nanomed. 2016, 11, 1889.

[16] W.-S. Kuo, C.-N. Chang, Y.-T. Chang, M.-H. Yang, Y.-H. Chien, S.-J. Chen, C.-S. Yeh, Angew. Chem. Int. Ed. 2010, 49, 2711.

[17] I. Marangon, C. Ménard-Moyon, A. K. A. Silva, A. Bianco, N. Luciani, F. Gazeau, Carbon 2016, 97, 110 .

[18] D. Mertz, O. Sandre, S. Bégin-Colin, Biochim. Biophys. Acta BBA - Gen. Subj. 2017, 1861, 1617. 
[19] G. Reina, J. M. González-Domínguez, A. Criado, E. Vázquez, A. Bianco, M. Prato, Chem. Soc. Rev. 2017, 46, 4400.

[20] C. S. Brazel, Pharm. Res. 2009, 26, 644.

[21] A. Chilkoti, M. R. Dreher, D. E. Meyer, D. Raucher, Adv. Drug Deliv. Rev. 2002, 54, 613.

[22] A. Meddahi- Pellé, A. Legrand, A. Marcellan, L. Louedec, D. Letourneur, L. Leibler, Angew. Chem. Int. Ed. 2014, 53, 6369.

[23] A. R. Boccaccini, M. Erol, W. J. Stark, D. Mohn, Z. Hong, J. F. Mano, Compos. Sci. Technol. 2010, 70, 1764.

[24] S. Rafieian, H. Mirzadeh, H. Mahdavi, M. E. Masoumi, Sci. Eng. Compos. Mater. 2019, 26, 154.

[25] L. N. Woodard, M. A. Grunlan, ACS Macro Lett. 2018, 7, 976.

[26] H. D. Kim, S. Amirthalingam, S. L. Kim, S. S. Lee, J. Rangasamy, N. S. Hwang, Adv. Healthc. Mater. 2017, 6, 1700612.

[27] W. L. Murphy, T. C. McDevitt, A. J. Engler, Nat. Mater. 2014, 13, 547.

[28] S. Franz, S. Rammelt, D. Scharnweber, J. C. Simon, Biomaterials 2011, 32, 6692.

[29] C. Rungsiyakull, Q. Li, G. Sun, W. Li, M. V. Swain, Biomaterials 2010, 31, 7196.

[30] K. Madhavan Nampoothiri, N. R. Nair, R. P. John, Bioresour. Technol. 2010, 101, 8493.

[31] G. D. Nicodemus, S. J. Bryant, Tissue Eng. Part B Rev. 2008, 14, 149.

[32] A. M. Hawkins, N. S. Satarkar, J. Z. Hilt, Pharm. Res. 2009, 26, 667.

[33] Y. Fu, W. J. Kao, J. Biomed. Mater. Res. A 2011, 98A, 201.

[34] J. H. Park, Y. H. Bae, Biomaterials 2002, 23, 1797.

[35] J. Carrey, V. Connord, M. Respaud, Appl. Phys. Lett. 2013, 102, 232404.

[36] G. V. Podaru, V. Chikan, P. Prakash, J. Phys. Chem. C 2016, 120, 2386.

[37] H. Gong, R. Peng, Z. Liu, Adv. Drug Deliv. Rev. 2013, 65, 1951.

[38] H. Kim, K. Chung, S. Lee, D. H. Kim, H. Lee, Wiley Interdiscip. Rev. Nanomed. Nanobiotechnol. 2016, 8, 23.

[39] T. Nagaya, S. Okuyama, F. Ogata, Y. Maruoka, P. L. Choyke, H. Kobayashi, Cancer Sci. 2018, 109, 1902.

[40] S.-R. Tsai, M. R. Hamblin, J. Photochem. Photobiol. B 2017, 170, 197.

[41] C. Wang, H. Tao, L. Cheng, Z. Liu, Biomaterials 2011, 32, 6145.

[42] E. Guisasola, L. Asín, L. Beola, J. M. de la Fuente, A. Baeza, M. Vallet-Regí, ACS Appl. Mater. Interfaces 2018, 10, 12518.

[43] A. Zakharchenko, N. Guz, A. M. Laradji, E. Katz, S. Minko, Nat. Catal. 2018, 1, 73.

[44] J. F. Hainfeld, F. A. Dilmanian, Z. Zhong, D. N. Slatkin, J. A. Kalef-Ezra, H. M. Smilowitz, Phys. Med. Biol. 2010, 55, 3045.

[45] J. F. Hainfeld, F. A. Dilmanian, D. N. Slatkin, H. M. Smilowitz, J. Pharm. Pharmacol. 2008, 60, 977.

[46] K. Matsumoto, H. Saitoh, T. L. H. Doan, A. Shiro, K. Nakai, A. Komatsu, M. Tsujimoto, R. Yasuda, T. Kawachi, T. Tajima, F. Tamanoi, Sci. Rep. 2019, 9, 1.

[47] M. Okino, S. Coutelou, K. Mizuno, T. Yanagitani, M. Matsukawa, Appl. Phys. Lett. 2013, 103, 103701.

[48] F. Prieur, V. Pialoux, J.-L. Mestas, P. Mury, S. Skinner, C. Lafon, Ultrason. Sonochem. 2015, 26, 193.

[49] D. P. Rabussay, G. S. Nanda, P. M. Goldfarb, Technol. Cancer Res. Treat. 2002, 1, 71.

[50] R. Rastogi, S. Anand, V. Koul, Drug Dev. Ind. Pharm. 2010, 36, 1303.

[51] D. L. West, S. B. White, Z. Zhang, A. C. Larson, R. A. Omary, Assessment and optimization of electroporation-assisted tumoral nanoparticle uptake in a nude mouse model of pancreatic ductal adenocarcinoma. Int. J. Nanomedicine 2014.

[52] S. Kossatz, R. Ludwig, H. Dähring, V. Ettelt, G. Rimkus, M. Marciello, G. Salas, V. Patel, F. J. Teran, I. Hilger, Pharm. Res. 2014, 31, 3274.

[53] S. Mitragotri, Nat. Rev. Drug Discov. 2005, 4, 255. 
[54] S. Laurent, D. Forge, M. Port, A. Roch, C. Robic, L. Vander Elst, R. N. Muller, Chem. Rev. 2008, 108, 2064.

[55] H. B. Na, I. C. Song, T. Hyeon, Adv. Mater. 2009, 21, 2133.

[56] G. F. Goya, L. Asín, M. R. Ibarra, Int. J. Hyperthermia 2013, 29, 810.

[57] I. Hilger, Int. J. Hyperthermia 2013, 29, 828.

[58] B. Thiesen, A. Jordan, Int. J. Hyperthermia 2008, 24, 467.

[59] G. Glöckl, R. Hergt, M. Zeisberger, S. Dutz, S. Nagel, W. Weitschies, J. Phys. Condens. Matter 2006, 18, S2935.

[60] R. Hergt, S. Dutz, R. Müller, M. Zeisberger, J. Phys. Condens. Matter 2006, 18, S2919.

[61] E. A. Perigo, G. Hemery, O. Sandre, D. Ortega, E. Garaio, F. Plazaola, F. J. Teran, Appl. Phys. Rev. 2015, 2, 041302.

[62] B. D. Cullity, C. D. Graham, Introduction to magnetic materials; John Wiley \& Sons, 2011.

[63] S. Dutz, R. Hergt, Nanotechnology 2014, 25, 452001.

[64] R. Hergt, S. Dutz, J. Magn. Magn. Mater. 2007, 311, 187.

[65] Magforce - The Nanomedicine Company.

[66] K. Maier-Hauff, R. Rothe, R. Scholz, U. Gneveckow, P. Wust, B. Thiesen, A. Feussner, A. von Deimling, N. Waldoefner, R. Felix, J. Neurooncol. 2007, 81, 53.

[67] K. Maier-Hauff, F. Ulrich, D. Nestler, H. Niehoff, P. Wust, B. Thiesen, H. Orawa, V. Budach, A. Jordan, J. Neurooncol. 2011, 103, 317.

[68] A. E. Deatsch, B. A. Evans, J. Magn. Magn. Mater. 2014, 354, 163.

[69] J. Kolosnjaj-Tabi, R. Di Corato, L. Lartigue, I. Marangon, P. Guardia, A. K. Silva, N. Luciani, O. Clément, P. Flaud, J. V. Singh, ACS Nano 2014, 8, 4268.

[70] J.-H. Lee, J. Jang, J. Choi, S. H. Moon, S. Noh, J. Kim, J.-G. Kim, I.-S. Kim, K. I. Park, J. Cheon, Nat. Nanotechnol. 2011, 6, 418.

[71] M. Kallumadil, M. Tada, T. Nakagawa, M. Abe, P. Southern, Q. A. Pankhurst, J. Magn. Magn. Mater. 2009, 321, 1509.

[72] R. E. Rosensweig, J. Magn. Magn. Mater. 2002, 252, 370.

[73] A. Makridis, S. Curto, G. C. van Rhoon, T. Samaras, M. Angelakeris, J. Phys. Appl. Phys. 2019, 52, 255001.

[74] P. Guardia, R. Di Corato, L. Lartigue, C. Wilhelm, A. Espinosa, M. Garcia-Hernandez, F. Gazeau, L. Manna, T. Pellegrino, ACS Nano 2012, 6, 3080.

[75] P. Hugounenq, M. Levy, D. Alloyeau, L. Lartigue, E. Dubois, V. Cabuil, C. Ricolleau, S. Roux, C. Wilhelm, F. Gazeau, J. Phys. Chem. C 2012, 116, 15702.

[76] C. S. Kumar, F. Mohammad, Adv. Drug Deliv. Rev. 2011, 63, 789.

[77] J.-H. Lee, Y.-M. Huh, Y. Jun, J. Seo, J. Jang, H.-T. Song, S. Kim, E.-J. Cho, H.-G. Yoon, J.-S. Suh, Nat. Med. 2007, 13, 95.

[78] V. Patsula, M. Moskvin, S. Dutz, D. Horák, J. Phys. Chem. Solids 2016, 88, 24.

[79] J.-P. Fortin, C. Wilhelm, J. Servais, C. Ménager, J.-C. Bacri, F. Gazeau, J. Am. Chem. Soc. 2007, 129, 2628.

[80] A.-H. Lu, E. L. Salabas, F. Schüth, Angew. Chem. Int. Ed. 2007, 46, 1222.

[81] J. Park, K. An, Y. Hwang, J.-G. Park, H.-J. Noh, J.-Y. Kim, J.-H. Park, N.-M. Hwang, T. Hyeon, Nat. Mater. 2004, 3, 891.

[82] S. Sun, H. Zeng, D. B. Robinson, S. Raoux, P. M. Rice, S. X. Wang, G. Li, J. Am. Chem. Soc. 2004, 126, 273.

[83] C. Martinez-Boubeta, K. Simeonidis, A. Makridis, M. Angelakeris, O. Iglesias, P. Guardia, A. Cabot, L. Yedra, S. Estradé, F. Peiró, Sci. Rep. 2013, 3, 1652.

[84] A. Walter, C. Billotey, A. Garofalo, C. Ulhaq-Bouillet, C. Lefèvre, J. Taleb, S. Laurent, L. Vander Elst, R. N. Muller, L. Lartigue, Chem. Mater. 2014, 26, 5252.

[85] C. Blanco-Andujar, D. Ortega, P. Southern, Q. A. Pankhurst, N. T. K. Thanh, Nanoscale 2015, 7, 1768. 
[86] A. Sathya, P. Guardia, R. Brescia, N. Silvestri, G. Pugliese, S. Nitti, L. Manna, T. Pellegrino, Chem. Mater. 2016, 28, 1769.

[87] G. Cotin, C. Blanco-Andujar, D.-V. Nguyen, C. Affolter, S. Boutry, A. Boos, P. Ronot, B. Uring-Lambert, P. Choquet, P. E. Zorn, D. Mertz, S. Laurent, R. N. Muller, F. Meyer, D. F. Flesch, S. Begin-Colin, Nanotechnology 2019, 30, 374002.

[88] F. Perton, M. Tasso, G. A. Muñoz Medina, M. Ménard, C. Blanco-Andujar, E. Portiansky, M. B. F. van Raap, D. Bégin, F. Meyer, S. Begin-Colin, D. Mertz, Appl. Mater. Today 2019, 16, 301.

[89] V. Mameli, A. Musinu, A. Ardu, G. Ennas, D. Peddis, D. Niznansky, C. Sangregorio, C. Innocenti, N. T. K. Thanh, C. Cannas, Nanoscale 2016, 8, 10124.

[90] P. de la Presa, Y. Luengo, M. Multigner, R. Costo, M. P. Morales, G. Rivero, A. Hernando, $J$. Phys. Chem. C 2012, 116, 25602.

[91] D. Serantes, K. Simeonidis, M. Angelakeris, O. Chubykalo-Fesenko, M. Marciello, M. del P. Morales, D. Baldomir, C. Martinez-Boubeta, J. Phys. Chem. C 2014, 118, 5927.

[92] R. Mejías, P. Hernández Flores, M. Talelli, J. L. Tajada-Herráiz, M. E. F. Brollo, Y. Portilla, M. P. Morales, D. F. Barber, ACS Appl. Mater. Interfaces 2019, 11, 340.

[93] F. Mazuel, A. Espinosa, N. Luciani, M. Reffay, R. Le Borgne, L. Motte, K. Desboeufs, A. Michel, T. Pellegrino, Y. Lalatonne, C. Wilhelm, ACS Nano 2016, 10, 7627.

[94] A. Battigelli, C. Ménard-Moyon, A. Bianco, J. Mater. Chem. B 2014, 2, 6144.

[95] K. S. Novoselov, A. K. Geim, S. V. Morozov, D. Jiang, Y. Zhang, S. V. Dubonos, I. V. Grigorieva, A. A. Firsov, science 2004, 306, 666.

[96] W. S. Hummers Jr, R. E. Offeman, J. Am. Chem. Soc. 1958, 80, 1339.

[97] I. Janowska, K. Chizari, O. Ersen, S. Zafeiratos, D. Soubane, V. Da Costa, V. Speisser, C. Boeglin, M. Houllé, D. Bégin, Nano Res. 2010, 3, 126.

[98] A. Ciesielski, P. Samorì, Chem. Soc. Rev. 2014, 43, 381.

[99] B. Schmaltz, T. Weil, K. Müllen, Adv. Mater. 2009, 21, 1067.

[100] P.-C. Ma, N. A. Siddiqui, G. Marom, J.-K. Kim, Compos. Part Appl. Sci. Manuf. 2010, 41, 1345.

[101] I. A. Vacchi, C. Ménard-Moyon, A. Bianco, Phys. Sci. Rev. 2017, 2.

[102] C. Wells, O. Vollin- Bringel, V. Fiegel, S. Harlepp, B. V. der Schueren, S. Bégin- Colin, D. Bégin, D. Mertz, Adv. Funct. Mater. 2018, 28, 1706996.

[103] V. Fiegel, S. Harlepp, S. Begin-Colin, D. Begin, D. Mertz, Chem. - Eur. J. 2018, 24, 4662.

[104] P. M. Bendix, S. N. S. Reihani, L. B. Oddershede, ACS Nano 2010, 4, 2256.

[105] L. R. Hirsch, R. J. Stafford, J. A. Bankson, S. R. Sershen, B. Rivera, R. E. Price, J. D. Hazle, N. J. Halas, J. L. West, Proc. Natl. Acad. Sci. 2003, 100, 13549.

[106] W. I. Choi, A. Sahu, Y. H. Kim, G. Tae, Ann. Biomed. Eng. 2012, 40, 534.

[107] L. Dykman, N. Khlebtsov, Chem. Soc. Rev. 2012, 41, 2256.

[108] C. M. Cobley, L. Au, J. Chen, Y. Xia, Expert Opin. Drug Deliv. 2010, 7, 577.

[109] A. Hatef, S. Fortin-Deschênes, E. Boulais, F. Lesage, M. Meunier, Int. J. Heat Mass Transf. 2015, 89, 866.

[110] Z. Li, H. Huang, S. Tang, Y. Li, X.-F. Yu, H. Wang, P. Li, Z. Sun, H. Zhang, C. Liu, Biomaterials 2016, 74, 144.

[111] S. M. R. Safaee, M. Janipour, M. A. Karami, Appl. Opt. 2015, 54, 8313.

[112] D. Lapotko, E. Lukianova, M. Potapnev, O. Aleinikova, A. Oraevsky, Cancer Lett. 2006, 239, 36.

[113] V. P. Zharov, E. N. Galitovskaya, C. Johnson, T. Kelly, Lasers Surg. Med. Off. J. Am. Soc. Laser Med. Surg. 2005, 37, 219.

[114] J. Croissant, D. Salles, M. Maynadier, O. Mongin, V. Hugues, M. Blanchard-Desce, X. Cattoën, M. Wong Chi Man, A. Gallud, M. Garcia, Chem. Mater. 2014, 26, 7214.

[115] J. Croissant, M. Maynadier, O. Mongin, V. Hugues, M. Blanchard-Desce, A. Chaix, X. Cattoën, M. Wong Chi Man, A. Gallud, M. Gary-Bobo, Small 2015, 11, 295. 
[116] V. Dixit, J. Van den Bossche, D. M. Sherman, D. H. Thompson, R. P. Andres, Bioconjug. Chem. 2006, 17, 603.

[117] W. I. Choi, J.-Y. Kim, C. Kang, C. C. Byeon, Y. H. Kim, G. Tae, ACS Nano 2011, 5, 1995.

[118] E. B. Dickerson, E. C. Dreaden, X. Huang, I. H. El-Sayed, H. Chu, S. Pushpanketh, J. F. McDonald, M. A. El-Sayed, Cancer Lett. 2008, 269, 57.

[119] G. P. Goodrich, L. Bao, K. L. Gill-Sharp, K. L. Sang, J. C. Wang, J. D. Payne, J. Biomed. Opt. 2010, 15, 018001 .

[120] A. S. Hoffman, Adv. Drug Deliv. Rev. 2012, 64, 18.

[121] M. Patenaude, T. Hoare, ACS Macro Lett. 2012, 1, 409.

[122] B. Verdejo, F. Rodríguez-Llansola, B. Escuder, J. F. Miravet, P. Ballester, Chem. Commun. 2011, 47, 2017.

[123] J. Li, D. J. Mooney, Nat. Rev. Mater. 2016, 1, 16071.

[124] K. Haraguchi, Macromol. Symp. 2007, 256, 120.

[125] B. Balakrishnan, M. Mohanty, P. R. Umashankar, A. Jayakrishnan, Biomaterials 2005, 26, 6335.

[126] M. S. Shoichet, Macromolecules 2009, 43, 581.

[127] X. Z. Shu, S. Ahmad, Y. Liu, G. D. Prestwich, J. Biomed. Mater. Res. A 2006, 79, 902.

[128] L. Yu, J. Ding, Chem. Soc. Rev. 2008, 37, 1473.

[129] K. A. Smeds, M. W. Grinstaff, J. Biomed. Mater. Res. Off. J. Soc. Biomater. Jpn. Soc. Biomater. 2001, 54, 115.

[130] S. R. Van Tomme, G. Storm, W. E. Hennink, Int. J. Pharm. 2008, 355, 1.

[131] C. Hiemstra, L. J. van der Aa, Z. Zhong, P. J. Dijkstra, J. Feijen, Biomacromolecules 2007, 8, 1548.

[132] G. Tae, Y.-J. Kim, W.-I. Choi, M. Kim, P. S. Stayton, A. S. Hoffman, Biomacromolecules 2007, 8, 1979.

[133] B. Balakrishnan, A. Jayakrishnan, Biomaterials 2005, 26, 3941.

[134] J. Maia, L. Ferreira, R. Carvalho, M. A. Ramos, M. H. Gil, Polymer 2005, 46, 9604.

[135] B. Vernon, A. Gutowska, S. Wan Kim, Y. Han Bae, In Macromolecular Symposia; Wiley Online Library, 1996; Vol. 109, pp. 155-167.

[136] X.-Z. Zhang, D.-Q. Wu, G.-M. Sun, C.-C. Chu, Macromol. Biosci. 2003, 3, 87.

[137] B. Jeong, Y. H. Bae, S. W. Kim, J. Biomed. Mater. Res. Off. J. Soc. Biomater. Jpn. Soc. Biomater. Aust. Soc. Biomater. Korean Soc. Biomater. 2000, 50, 171.

[138] B. Jeong, S. W. Kim, Y. H. Bae, Adv. Drug Deliv. Rev. 2012, 64, 154.

[139] J. Wang, C. M. Valmikinathan, W. Liu, C. T. Laurencin, X. Yu, J. Biomed. Mater. Res. A 2010, $93 A, 753$.

[140] X. Wang, B. Ding, B. Li, Mater. Today 2013, 16, 229.

[141] J. Ding, J. Zhang, J. Li, D. Li, C. Xiao, H. Xiao, H. Yang, X. Zhuang, X. Chen, Prog. Polym. Sci. 2019, 90, 1.

[142] J. Xue, T. Wu, Y. Dai, Y. Xia, Chem. Rev. 2019, 119, 5298.

[143] G. Yang, X. Li, Y. He, J. Ma, G. Ni, S. Zhou, Prog. Polym. Sci. 2018, 81, 80.

[144] D. Li, Y. Xia, Nano Lett. 2004, 4, 933.

[145] Y. Liu, J. Luo, C. Helleu, M. Behr, H. Ba, T. Romero, A. Hébraud, G. Schlatter, O. Ersen, D. S. Su, J. Mater. Chem. A 2017, 5, 2151.

[146] P. Katta, M. Alessandro, R. D. Ramsier, G. G. Chase, Nano Lett. 2004, 4, 2215.

[147] C. R. Wittmer, A. Hébraud, S. Nedjari, G. Schlatter, Polymer 2014, 55, 5781.

[148] Q. Zhang, Y. Li, Z. Y. W. Lin, K. K. Wong, M. Lin, L. Yildirimer, X. Zhao, Drug Discov. Today 2017, 22, 1351.

[149] A. Garcia Garcia, A. Hébraud, J.-L. Duval, C. R. Wittmer, L. Gaut, D. Duprez, C. Egles, F. Bedoui, G. Schlatter, C. Legallais, ACS Biomater. Sci. Eng. 2018, 4, 3317.

[150] K. Belanger, G. Schlatter, A. Hébraud, F. Marin, S. Testelin, S. Dakpé, B. Devauchelle, C. Egles, Health Sci. Rep. 2018, 1, e86. 
[151] A. C. Balazs, T. Emrick, T. P. Russell, Science 2006, 314, 1107.

[152] F. Caruso, Adv. Mater. 2001, 13, 11.

[153] A. D. Bannerman, X. Li, W. Wan, Acta Biomater. 2017, 58, 376.

[154] R. A. Frimpong, S. Fraser, J. Z. Hilt, J. Biomed. Mater. Res. A 2007, 80A, 1.

[155] A. Servant, V. Leon, D. Jasim, L. Methven, P. Limousin, E. V. Fernandez- Pacheco, M. Prato, K. Kostarelos, Graphene- Based Electroresponsive Scaffolds as Polymeric Implants for On- Demand Drug Delivery. Adv. Healthc. Mater. 2014.

[156] P. Ilg, Soft Matter 2013, 9, 3465.

[157] Y. Wang, B. Li, Y. Zhou, D. Jia, Polym. Adv. Technol. 2008, 19, 1256.

[158] I. Gorelikov, L. M. Field, E. Kumacheva, J. Am. Chem. Soc. 2004, 126, 15938.

[159] J.-O. You, M. Rafat, G. J. C. Ye, D. T. Auguste, Nano Lett. 2011, 11, 3643.

[160] J. K. Oh, J. M. Park, Prog. Polym. Sci. 2011, 36, 168.

[161] A. Skardal, J. Zhang, L. McCoard, S. Oottamasathien, G. D. Prestwich, Adv. Mater. 2010, 22, 4736.

[162] A. K. Gaharwar, A. Patel, A. Dolatshahi-Pirouz, H. Zhang, K. Rangarajan, G. Iviglia, S.-R. Shin, M. A. Hussain, A. Khademhosseini, Biomater. Sci. 2015, 3, 46.

[163] C. M. Homenick, H. Sheardown, A. Adronov, J. Mater. Chem. 2010, 20, 2887.

[164] S. R. Shin, B. Aghaei- Ghareh- Bolagh, T. T. Dang, S. N. Topkaya, X. Gao, S. Y. Yang, S. M. Jung, J. H. Oh, M. R. Dokmeci, X. (Shirley) Tang, A. Khademhosseini, Adv. Mater. 2013, 25,6385 .

[165] E. Korina, O. Stoilova, N. Manolova, I. Rashkov, Macromol. Biosci. 2013, 13, 707.

[166] K. Lai, W. Jiang, J. Z. Tang, Y. Wu, B. He, G. Wang, Z. Gu, RSC Adv. 2012, 2, 13007.

[167] J. Meng, B. Xiao, Y. Zhang, J. Liu, H. Xue, J. Lei, H. Kong, Y. Huang, Z. Jin, N. Gu, Sci. Rep. 2013, 3, 2655.

[168] D. Shan, Y. Shi, S. Duan, Y. Wei, Q. Cai, X. Yang, Mater. Sci. Eng. C 2013, 33, 3498.

[169] Y. K. Sung, B. W. Ahn, T. J. Kang, J. Magn. Magn. Mater. 2012, 324, 916.

[170] C. Hu, W. Cui, Adv. Healthc. Mater. 2012, 1, 809.

[171] B. Song, C. Wu, J. Chang, Regen. Biomater. 2015, 2, 229.

[172] G.-M. Kim, A. Wutzler, H.-J. Radusch, G. H. Michler, P. Simon, R. A. Sperling, W. J. Parak, Chem. Mater. 2005, 17, 4949.

[173] Y. Y. Qi, Z. X. Tai, D. F. Sun, J. T. Chen, H. B. Ma, X. B. Yan, B. Liu, Q. J. Xue, J. Appl. Polym. Sci. 2013, 127, 1885.

[174] Y. Luo, H. Shen, Y. Fang, Y. Cao, J. Huang, M. Zhang, J. Dai, X. Shi, Z. Zhang, ACS Appl. Mater. Interfaces 2015, 7, 6331.

[175] H. Zhu, M. Du, M. Zou, C. Xu, N. Li, Y. Fu, J. Mater. Chem. 2012, 22, 9301.

[176] A. Celebioglu, Z. Aytac, O. C. Umu, A. Dana, T. Tekinay, T. Uyar, Carbohydr. Polym. 2014, 99, 808.

[177] L. Burke, C. J. Mortimer, D. J. Curtis, A. R. Lewis, R. Williams, K. Hawkins, T. G. Maffeis, C. J. Wright, Mater. Sci. Eng. C 2017, 70, 512.

[178] N. Lavielle, A. Hébraud, G. Schlatter, L. Thöny-Meyer, R. M. Rossi, A.-M. Popa, ACS Appl. Mater. Interfaces 2013, 5, 10090.

[179] N. Lavielle, A. Hébraud, L. Thöny- Meyer, R. M. Rossi, G. Schlatter, Macromol. Mater. Eng. 2017, 302, 1600458.

[180] N. Shokraei, S. Asadpour, S. Shokraei, M. N. Sabet, R. Faridi- Majidi, H. Ghanbari, Microsc. Res. Tech. 2019, 82, 1316.

[181] S. Nedjari, A. Hébraud, S. Eap, S. Siegwald, C. Mélart, N. Benkirane-Jessel, G. Schlatter, RSC Adv. 2015, 5, 83600.

[182] A. Amarjargal, L. D. Tijing, C.-H. Park, I.-T. Im, C. S. Kim, Eur. Polym. J. 2013, 49, 3796.

[183] S. Xiao, W. Xu, H. Ma, X. Fang, RSC Adv. 2011, 2, 319.

[184] S. Xiao, M. Shen, R. Guo, S. Wang, X. Shi, J. Phys. Chem. C 2009, 113, 18062.

[185] B. Zhou, X. Jin, H. Liang, J. Li, S. Liu, Y. Li, Y. Chen, B. Li, RSC Adv. 2015, 5, 26965. 
[186] J. Chen, L. Yang, Y. Liu, G. Ding, Y. Pei, J. Li, G. Hua, J. Huang, In Macromolecular Symposia; Wiley Online Library, 2005; Vol. 225, pp. 71-80.

[187] T.-Y. Liu, S.-H. Hu, T.-Y. Liu, D.-M. Liu, S.-Y. Chen, Langmuir 2006, 22, 5974.

[188] T.-Y. Liu, S.-H. Hu, K.-H. Liu, D.-M. Liu, S.-Y. Chen, J. Controlled Release 2008, 126, 228.

[189] N. S. Satarkar, J. Z. Hilt, J. Controlled Release 2008, 130, 246.

[190] S. B. Campbell, M. Patenaude, T. Hoare, Biomacromolecules 2013, 14, 644.

[191] Y.-J. Kim, M. Ebara, T. Aoyagi, Adv. Funct. Mater. 2013, 23, 5753.

[192] S. A. Meenach, J. Z. Hilt, K. W. Anderson, Acta Biomater. 2010, 6, 1039.

[193] W. Xie, Q. Gao, Z. Guo, D. Wang, F. Gao, X. Wang, Y. Wei, L. Zhao, ACS Appl. Mater. Interfaces 2017, 9, 33660.

[194] S. A. Meenach, J. M. Shapiro, J. Z. Hilt, K. W. Anderson, J. Biomater. Sci. Polym. Ed. 2013, $24,1112$.

[195] T. Hoare, J. Santamaria, G. F. Goya, S. Irusta, D. Lin, S. Lau, R. Padera, R. Langer, D. S. Kohane, Nano Lett. 2009, 9, 3651.

[196] N. S. Satarkar, W. Zhang, R. E. Eitel, J. Z. Hilt, Lab. Chip 2009, 9, 1773.

[197] C. Cha, S. R. Shin, N. Annabi, M. R. Dokmeci, A. Khademhosseini, ACS Nano 2013, 7, 2891.

[198] S. Goenka, V. Sant, S. Sant, J. Controlled Release 2014, 173, 75.

[199] J. Wu, A. Chen, M. Qin, R. Huang, G. Zhang, B. Xue, J. Wei, Y. Li, Y. Cao, W. Wang, Nanoscale 2015, 7, 1655.

[200] S. R. Sershen, G. A. Mensing, M. Ng, N. J. Halas, D. J. Beebe, J. L. West, Adv. Mater. 2005, $17,1366$.

[201] S. R. Sershen, S. L. Westcott, N. J. Halas, J. L. West, J. Biomed. Mater. Res. 2000, 51, 293.

[202] B. Yan, J.-C. Boyer, D. Habault, N. R. Branda, Y. Zhao, J. Am. Chem. Soc. 2012, 134, 16558.

[203] X. Liu, P. Kruger, H. Maibach, P. B. Colditz, M. S. Roberts, Adv. Drug Deliv. Rev. 2014, 77, 40.

[204] S. Murdan, J. Controlled Release 2003, 92, 1.

[205] A. Servant, L. Methven, R. P. Williams, K. Kostarelos, Adv. Healthc. Mater. 2013, 2, 806.

[206] H.-W. Liu, S.-H. Hu, Y.-W. Chen, S.-Y. Chen, J. Mater. Chem. 2012, 22, 17311.

[207] J. Yun, J. S. Im, Y.-S. Lee, H.-I. Kim, Eur. Polym. J. 2011, 47, 1893.

[208] Y. Xia, J. Sun, L. Zhao, F. Zhang, X.-J. Liang, Y. Guo, M. D. Weir, M. A. Reynolds, N. Gu, H. H. K. Xu, Biomaterials 2018, 183, 151.

[209] H. Chen, J. Sun, Z. Wang, Y. Zhou, Z. Lou, B. Chen, P. Wang, Z. Guo, H. Tang, J. Ma, Y. Xia, N. Gu, F. Zhang, ACS Appl. Mater. Interfaces 2018, 10, 44279.

[210] J. Meng, Y. Zhang, X. Qi, H. Kong, C. Wang, Z. Xu, S. Xie, N. Gu, H. Xu, Nanoscale 2010, $2,2565$.

[211] H.-M. Yun, S.-J. Ahn, K.-R. Park, M.-J. Kim, J.-J. Kim, G.-Z. Jin, H.-W. Kim, E.-C. Kim, Biomaterials 2016, 85, 88.

[212] R. M. Erb, J. J. Martin, R. Soheilian, C. Pan, J. R. Barber, Adv. Funct. Mater. 2016, 26, 3859.

[213] R. Fuhrer, E. K. Athanassiou, N. A. Luechinger, W. J. Stark, Small 2009, 5, 383.

[214] N. Kato, Y. Takizawa, F. Takahashi, J. Intell. Mater. Syst. Struct. 1997, 8, 588.

[215] C. M. Yakacki, N. S. Satarkar, K. Gall, R. Likos, J. Z. Hilt, J. Appl. Polym. Sci. 2009, 112, 3166.

[216] J. Ramón- Azcón, S. Ahadian, M. Estili, X. Liang, S. Ostrovidov, H. Kaji, H. Shiku, M. Ramalingam, K. Nakajima, Y. Sakka, A. Khademhosseini, T. Matsue, Adv. Mater. 2013, 25, 4028.

[217] E. Wang, M. S. Desai, S.-W. Lee, Nano Lett. 2013, 13, 2826.

[218] Y. Sapir, S. Cohen, G. Friedman, B. Polyak, Biomaterials 2012, 33, 4100.

[219] T. Sun, Q. Shi, Q. Huang, H. Wang, X. Xiong, C. Hu, T. Fukuda, Acta Biomater. 2018, 66, 272.

[220] Y. Liu, K. Xu, Q. Chang, M. A. Darabi, B. Lin, W. Zhong, M. Xing, Adv. Mater. 2016, 28, 7758. 
[221] S. R. Shin, H. Bae, J. M. Cha, J. Y. Mun, Y.-C. Chen, H. Tekin, H. Shin, S. Farshchi, M. R. Dokmeci, S. Tang, A. Khademhosseini, ACS Nano 2012, 6, 362.

[222] S. R. Shin, S. M. Jung, M. Zalabany, K. Kim, P. Zorlutuna, S. bok Kim, M. Nikkhah, M. Khabiry, M. Azize, J. Kong, K. Wan, T. Palacios, M. R. Dokmeci, H. Bae, X. (Shirley) Tang, A. Khademhosseini, ACS Nano 2013, 7, 2369.

[223] T. Dvir, B. P. Timko, M. D. Brigham, S. R. Naik, S. S. Karajanagi, O. Levy, H. Jin, K. K. Parker, R. Langer, D. S. Kohane, Nat. Nanotechnol. 2011, 6, 720.

[224] M. Antman-Passig, O. Shefi, Nano Lett. 2016, 16, 2567.

[225] O. Z. Fisher, A. Khademhosseini, R. Langer, N. A. Peppas, Acc. Chem. Res. 2009, 43, 419.

[226] N. A. Peppas, J. Z. Hilt, J. B. Thomas, Nanotechnology in therapeutics: Current technology and applications; Horizon Scientific Press, 2007.

[227] B. V. Slaughter, S. S. Khurshid, O. Z. Fisher, A. Khademhosseini, N. A. Peppas, Adv. Mater. 2009, 21, 3307.

[228] D. S. Hsieh, R. Langer, J. Folkman, Proc. Natl. Acad. Sci. 1981, 78, 1863.

[229] M. Bikram, A. M. Gobin, R. E. Whitmire, J. L. West, J. Controlled Release 2007, 123, 219.

[230] E. Miyako, H. Nagata, K. Hirano, T. Hirotsu, Small 2008, 4, 1711.

[231] A. Paul, A. Hasan, H. A. Kindi, A. K. Gaharwar, V. T. Rao, M. Nikkhah, S. R. Shin, D. Krafft, M. R. Dokmeci, D. Shum-Tim, ACS Nano 2014, 8, 8050.

[232] T. Miyata, T. Uragami, K. Nakamae, Adv. Drug Deliv. Rev. 2002, 54, 79.

[233] J. Kost, J. Wolfrum, R. Langer, J. Biomed. Mater. Res. 1987, 21, 1367.

[234] O. Saslawski, C. Weingarten, J. P. Benoit, P. Couvreur, Life Sci. 1988, 42, 1521.

[235] R. Du, J. Wu, L. Chen, H. Huang, X. Zhang, J. Zhang, Small 2014, 10, 1387.

[236] Y. Zhang, B. Yang, X. Zhang, L. Xu, L. Tao, S. Li, Y. Wei, Chem. Commun. 2012, 48, 9305.

[237] E. A. Appel, M. W. Tibbitt, M. J. Webber, B. A. Mattix, O. Veiseh, R. Langer, Nat. Commun. 2015, 6, 6295.

[238] J. Guo, B. L. Tardy, A. J. Christofferson, Y. Dai, J. J. Richardson, W. Zhu, M. Hu, Y. Ju, J. Cui, R. R. Dagastine, I. Yarovsky, F. Caruso, Nat. Nanotechnol. 2016, 11, 1105.

[239] A. Espinosa, M. Bugnet, G. Radtke, S. Neveu, G. A. Botton, C. Wilhelm, A. Abou-Hassan, Nanoscale 2015, 7, 18872.

[240] F.-X. Coudert, Chem. Mater. 2015, 27, 1905.

[241] J. Guo, H. Sun, K. Alt, B. L. Tardy, J. J. Richardson, T. Suma, H. Ejima, J. Cui, C. E. Hagemeyer, F. Caruso, Adv. Healthc. Mater. 2015, 4, 1796.

[242] Z. Tian, X. Yao, K. Ma, X. Niu, J. Grothe, Q. Xu, L. Liu, S. Kaskel, Y. Zhu, ACS Omega 2017, 2, 1249.

[243] Y. Li, J. Jin, D. Wang, J. Lv, K. Hou, Y. Liu, C. Chen, Z. Tang, Nano Res. 2018, 11, 3294.

[244] M.-X. Wu, Y.-W. Yang, Adv. Mater. 2017, 29, 1606134. 


\section{Bibliography of authors}

Damien Mertz is a Researcher at the Centre National de la Recherche Scientifique (CNRS) working at the Institut de Physique et Chimie des Matériaux de Strasbourg (IPCMS) since 2013. He obtained his $\mathrm{PhD}$ degree in physical chemistry from the University of Strasbourg in 2008. Then, he was a postdoctoral fellow at the University of Melbourne, Australia, to develop mesoporous silica-templated protein capsules for drug delivery applications (20092011). His current research activity at CNRS is focused on the design of functional mesoporous silica nanocomposites such as magnetic core-shells, and carbon-based nanocomposites, for therapy (drug delivery, magnetic hyperthermia, phototherapy) and imaging (MRI, fluorescence) applications.

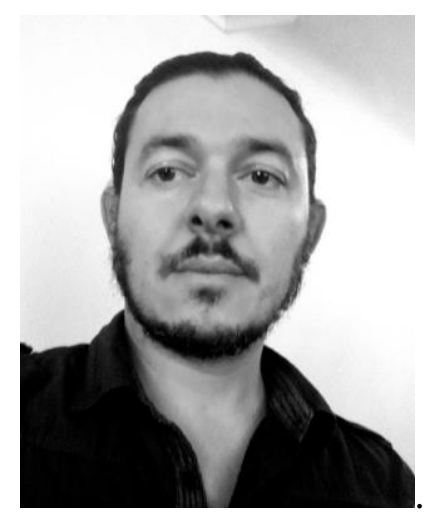

Anne Hébraud is an Associate Professor at the University of Strasbourg, working in the Department of Polymer Engineering of the Institute of Chemistry and Processes for Energy Environment and Health (ICPEES). She received her $\mathrm{PhD}$ in polymer physical chemistry from the University Pierre et Marie Curie, Paris. Her current research is focused on the preparation of polymer colloids or electrospun structured scaffolds for diverse applications including tissue engineering and controlled drug delivery.

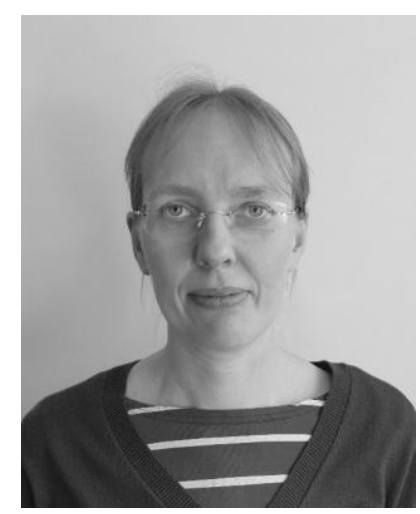


Biocompatible nanocomposite polymer scaffolds responding remotely to external fields (magnetic, electric, light) are envisioned as new implantable materials having therapeutic and imaging functionalities. They are designed to achieve a controlled drug delivery for various diseases, or a stimuli-induced cellular response for tissue engineering applications.

Keywords: responsive nanocomposites, external stimuli, polymer scaffolds, drug release, tissue engineering

Damien Mertz*, Sebastien Harlepp, Jacky Goetz, Dominique Bégin, Guy Schlatter, Sylvie Bégin-Colin, Anne Hébraud

*Corresponding author: damien.mertz@ipcms.unistra.fr

Nanocomposite Polymer Scaffolds Responding Under External Stimuli for Drug Delivery and Tissue Engineering Applications

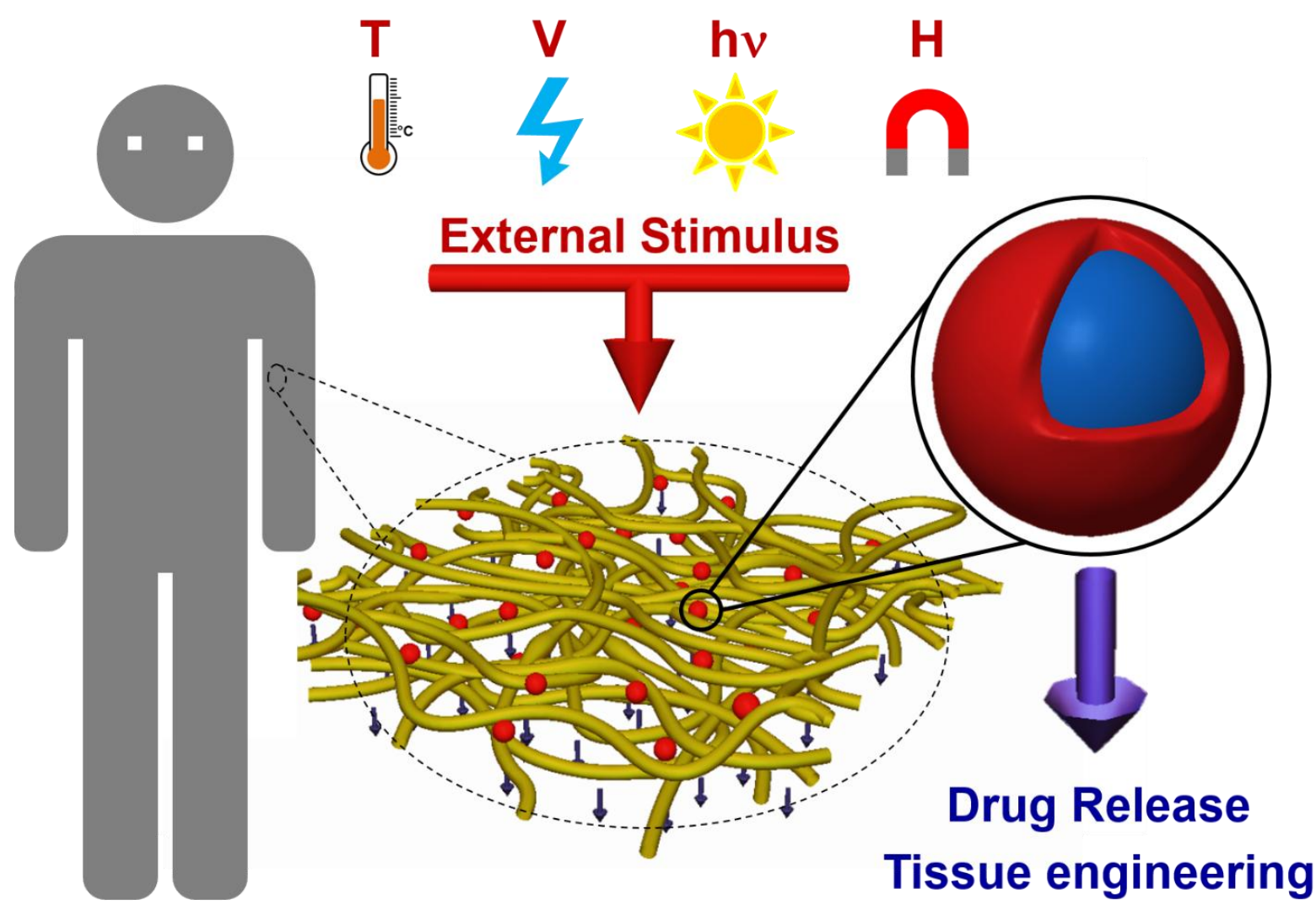

